\title{
Evaluation of WRF Forecasts of Tornadic and Nontornadic Outbreaks When Initialized with Synoptic-Scale Input
}

\author{
Chad M. Shafer And ANDrew E. Mercer \\ Cooperative Institute for Mesoscale Meteorological Studies, and School of Meteorology, University of Oklahoma, Norman, Oklahoma
}

\author{
Charles A. Doswell III
}

Cooperative Institute for Mesoscale Meteorological Studies, University of Oklahoma, Norman, Oklahoma

Michael B. Richman AND LANCE M. LesLiE

School of Meteorology, University of Oklahoma, Norman, Oklahoma

(Manuscript received 13 March 2008, in final form 15 September 2008)

\begin{abstract}
Uncertainty exists concerning the links between synoptic-scale processes and tornado outbreaks. With continuously improving computer technology, a large number of high-resolution model simulations can be conducted to study these outbreaks to the storm scale, to determine the degree to which synoptic-scale processes appear to influence the occurrence of tornado outbreaks, and to determine how far in advance these processes are important. To this end, 50 tornado outbreak simulations are compared with 50 primarily nontornadic outbreak simulations initialized with synoptic-scale input using the Weather Research and Forecasting (WRF) mesoscale model to determine if the model is able to distinguish the outbreak type 1,2, and 3 days in advance of the event. The model simulations cannot resolve tornadoes explicitly; thus, the use of meteorological covariates (in the form of numerous severe-weather parameters) is necessary to determine whether or not the model is predicting a tornado outbreak. Results indicate that, using the covariates, the WRF model can discriminate outbreak type consistently at least up to 3 days in advance. The severe-weather parameters that are most helpful in discriminating between outbreak types include low-level and deep-layer shear variables and the lifting condensation level. An analysis of the spatial structures and temporal evolution, as well as the magnitudes, of the severe-weather parameters is critical to diagnose the outbreak type correctly. Thermodynamic instability parameters are not helpful in distinguishing the outbreak type, primarily because of a strong seasonal dependence and convective modification in the simulations.
\end{abstract}

\section{Introduction}

An understanding of tornado outbreaks remains elusive despite an increasingly dense surface observation network, a consistent upper-air network of radiosondes, and continuously improving computer technology, which enables the use of powerful, highly resolved numerical simulation and prediction models. Recent events underscore the difficulty of this task; for example, the 3 May 1999 tornado outbreak was not evident to forecasters until a few hours before the event (Thompson

Corresponding author address: Chad Shafer, School of Meteorology, University of Oklahoma 120 David L. Boren Blvd., Suite 5900, Norman, OK 73072-7307.

E-mail: cmshafer@ou.edu and Edwards 2000). Other events, such as the 6 April 2001 severe-weather outbreak, were expected to produce numerous tornadoes but did not do so. These occasional misses and false alarms in the prediction of tornado outbreaks clearly indicate the need for increased understanding of these events and how they differ from similarly significant outbreaks with relatively few tornadoes (e.g., Stensrud et al. 1997, hereafter SCB97; Doswell and Bosart 2001; Doswell et al. 2006, hereafter D06).

The AMS Glossary of Meteorology (Glickman 2000) suggests a tornado outbreak has "multiple tornado occurrences associated with a particular synoptic-scale system." Most efforts to define tornado outbreaks focus on the numbers of tornadoes, but these numbers often vary from study to study (e.g., Pautz 1969; Galway 1975, 
1977; Grazulis 1993). Recently, D06 proposed a new methodology that, instead of defining tornado outbreaks formally, ranked these events in terms of meteorological significance and societal impact. This methodology incorporated a number of variables rather than focusing solely on the number of tornadoes. D06 stated that one of the primary goals of their methodology was to identify "the most important, prototypical cases for study" (p. 939). Furthermore, the ranked tornado outbreaks each were associated with one particular synoptic-scale system, in accordance with the AMS Glossary definition given above.

Uncertainty exists concerning the links between synoptic-scale processes and the likelihood of tornado outbreaks (e.g., Johns and Doswell 1992; Doswell et al. 1993; Doswell and Bosart 2001). These relatively recent assessments come after years of research focused on finding these links. The foundational studies were based on typical severe-weather environments, such as the identification of the "loaded gun" sounding (Fawbush and Miller 1952) and the development of three basic types of severe-weather soundings (Fawbush and Miller 1954). Beebe (1955) added the "inverted V" sounding as a potential severe-weather environment. Subsequently, research expanded to identify synoptic situations associated with such environments. Porter et al (1955) discussed typical synoptic-scale environments associated with squall lines. Beebe (1956) found some limited benefit in compositing rawinsonde data in a relatively small area in proximity to tornadoes. Miller (1972) identified five map types associated with tornado outbreaks. Reviews of these early investigations can be found in Schaefer (1986) and Doswell (2007a).

The primary convective mode often has major implications on whether or not a tornado outbreak will occur (Doswell and Evans 2003). Unfortunately, the correct prediction of storm type in an operational environment is a difficult task (SCB97), though recent studies (e.g., James et al. 2006) are beginning to shed light on this forecasting problem. SCB97 used a mesoscale model and analyzed forecast severe-weather parameters to determine if the model was able to distinguish between tornadic and nontornadic thunderstorms. Results of SCB97 were promising, but only nine cases were used in their study. They noted that the model appeared to work best with the most significant severeweather outbreaks. These outbreaks were considered "synoptically evident" (Doswell et al. 1993), whereas the more isolated tornado events used in the study were associated less clearly with synoptic-scale controls.

One approach to determining the influence of synopticscale processes on severe-weather outbreaks is to initialize mesoscale models with synoptic-scale input at various times preceding tornado outbreaks to determine if the model can accurately and consistently predict tornado outbreaks. These simulations should be compared to similar, yet distinct, severe-weather outbreaks in order to determine which factors are pertinent for the development of tornado outbreaks. It is not appropriate to compare tornado outbreaks to situations without significant severe convective storms for this purpose. Major tornado outbreaks are rare events; many days without tornado outbreaks are trivial to forecast as nonevents, whereas it is much more challenging to determine the likelihood of a tornado outbreak if severe convection is expected to be widespread. Hence, the results of this study were based on the condition that a severe-weather outbreak already had occurred.

Accordingly, we chose to compare tornado outbreak (TO) simulations with primarily nontornadic outbreak (PNO) simulations. In D06, PNOs were ranked using a similar methodology to that of TOs. D06 ensured that TOs and PNOs were mutually exclusive. TOs had to have at least seven tornadoes during a 24-h period, whereas PNOs were required to have fewer than seven. D06 again used a methodology that identified the most significant PNOs clearly associated with one synopticscale system.

Results presented here represent comparisons between TO and PNO simulations done in a purely diagnostic fashion. That is, the ability of mesoscale models to discriminate between TOs and PNOs has been evaluated in an a posteriori manner. The a priori determination of whether an outbreak will occur, or when to use the results of this research in an operational environment, is beyond the scope of this study.

\section{Data and methodology}

\section{a. The cases}

Using the methodologies for both TOs and PNOs as described in D06, we chose to simulate the top 50 outbreaks of each type. Fifty cases of each type were selected to ensure the stability and meaningfulness of the conclusions from the analyses, while ensuring that the cases were appropriately distinct in terms of the type of severe weather observed. The top 50 TOs were from the period 1970-2003 (Table 1), and the top 50 PNOs were from the period 1980-2003 (Table 2). Reasons for the differences in time periods are provided in D06. The TOs were most numerous during the spring and early summer (March-June) with a minor increase in November, whereas the PNOs were most numerous in the summer (June-August) when tornado outbreaks were at a minimum (Fig. 1). The cases used for this study 
TABLE 1. Forecast classifications for the 50 TOs on a particular date at 1-/2-/3-day classifications, separated by slashes. Lightface italics with an asterisk indicate little or no simulated convection within $6 \mathrm{~h}$ of the valid time in the innermost domain (D05). Boldface italicized entries indicate simulated convection featured supercellular characteristics.

\begin{tabular}{|c|c|c|}
\hline 17 Apr $1970 \boldsymbol{H} / \boldsymbol{M} / \mathrm{H}$ & 7 Jun $1984 \boldsymbol{H} / \mathrm{L} / \mathrm{M}$ & 19 Apr $1996 \boldsymbol{H} / L * / \boldsymbol{H}$ \\
\hline 21 Feb $1971 \boldsymbol{V H} / \boldsymbol{V H} / \mathrm{VH}$ & 31 May $1985 \boldsymbol{V H} / \mathrm{H} / \mathrm{H}$ & 1 Mar $1997 \boldsymbol{V H} / \mathrm{VH} / \boldsymbol{V H}$ \\
\hline 14 Dec 1971 VH/VH/VH & 8 May $1988 \boldsymbol{M} / \boldsymbol{H} / \boldsymbol{H}$ & 16 Apr $1998 \boldsymbol{V H} / \boldsymbol{V H} / \mathrm{H}$ \\
\hline 26 May $1973 \boldsymbol{H} / \mathrm{M} / L^{*}$ & 15 Nov $1988 \boldsymbol{V H} / \boldsymbol{V H} / \boldsymbol{V H}$ & 31 May $1998 \boldsymbol{V H} / \boldsymbol{V H} / \mathrm{H}$ \\
\hline 27 May $1973 \boldsymbol{V H} / \boldsymbol{V H} / \boldsymbol{H}$ & 13 Mar $1990 \boldsymbol{V H} / \boldsymbol{V H} / \mathrm{H}$ & $21 \mathrm{Jan} 1999 \mathrm{VH} / \mathrm{H} / \mathrm{H}$ \\
\hline 25 Sep $1973 \mathrm{H} / L * / \mathrm{H}$ & 2 Jun $1990 \boldsymbol{V H} / \boldsymbol{H} / \mathrm{VH}$ & 8 Apr $1999 \boldsymbol{H} / \boldsymbol{H} / \boldsymbol{H}$ \\
\hline 3 Apr $1974 \boldsymbol{V H} / \boldsymbol{V H} / \boldsymbol{V H}$ & 26 Apr $1991 \boldsymbol{H} / \boldsymbol{H} / \boldsymbol{H}$ & 3 May $1999 L * / L * / L^{*}$ \\
\hline 8 Jun 1974 H/VH/H & 15 Jun $1992 \boldsymbol{M} / \boldsymbol{M} / \mathbf{M}$ & 4 May $1999 \boldsymbol{V H} / \boldsymbol{V H} / \boldsymbol{H}$ \\
\hline $20 \mathrm{Mar} 1976 \mathrm{VH} / \mathrm{VH} / \boldsymbol{V H}$ & 16 Jun $1992 \boldsymbol{H} / \boldsymbol{H} / \boldsymbol{H}$ & 23 Apr $2000 \boldsymbol{M} / \boldsymbol{H} / \boldsymbol{H}$ \\
\hline 29 Mar $1976 \boldsymbol{V H} / \boldsymbol{V H} / \boldsymbol{V H}$ & 21 Nov 1992 VH/VH/VH & 24 Feb $2001 \boldsymbol{V H} / \mathrm{VH} / \boldsymbol{V H}$ \\
\hline 4 May $1977 \boldsymbol{H} / \boldsymbol{H} / \boldsymbol{H}$ & 22 Nov $1992 \boldsymbol{V H} / \mathrm{VH} / \boldsymbol{V H}$ & $23 \operatorname{Nov} 2001 \mathrm{VH} / H^{*} / V H^{*}$ \\
\hline 10 Apr $1979 \boldsymbol{H} / \boldsymbol{H} / \boldsymbol{H}$ & 7 May $1993 \mathrm{~L} / L^{*} / L^{*}$ & 24 Nov $2001 \boldsymbol{V H} / \mathrm{VH} / \mathrm{VH}$ \\
\hline 7 Apr $1980 \mathrm{VH} / \boldsymbol{V H} / \boldsymbol{V H}$ & 7 Jun $1993 \boldsymbol{H} / \mathrm{H} / \boldsymbol{V H}$ & $10 \mathrm{Nov} 2002 \boldsymbol{V H} / \mathrm{VH} / \mathrm{VH}$ \\
\hline 15 Mar $1982 \boldsymbol{V H} / \boldsymbol{H} / \mathrm{H}$ & 27 Mar 1994 VH/VH/VH & 4 May $2003 \boldsymbol{V H} / \boldsymbol{H} / \boldsymbol{H}$ \\
\hline 2 Apr $1982 \boldsymbol{V H} / \boldsymbol{V H} / \boldsymbol{V H}$ & 26 Apr $1994 \mathrm{~L} / L * / \mathrm{H}$ & 6 May $2003 \boldsymbol{M} / \mathrm{H} / L^{*}$ \\
\hline $28 \operatorname{Mar} 1984 \boldsymbol{V H} / \boldsymbol{V H} / \boldsymbol{V H}$ & 18 May $1995 \boldsymbol{H} / \boldsymbol{H} / \boldsymbol{V H}$ & 10 Мay $2003 \boldsymbol{V H} / \boldsymbol{V H} / \boldsymbol{V H}$ \\
\hline 26 Apr 1984 H/VH/VH & 27 May $1995 \boldsymbol{H} / \boldsymbol{H} / \mathrm{H}$ & \\
\hline
\end{tabular}

were centered on various geographic locations across the United States east of the Rocky Mountains (Fig. 2). The TOs commonly were centered on portions of the central and southern plains to the Mississippi Valley, with a lack of cases located in the Northeast (Fig. 2a). The PNOs were more numerous slightly northward of the TO maximum, with a noticeable minimum of cases in the lower Mississippi Valley (Fig. 2b).

Each outbreak day was from the period 1200 UTC on the date indicated in the tables to 1200 UTC on the following day $($ day +1$)$. Although severe weather peaked at various times during the $24-\mathrm{h}$ period depending on the outbreak, all but one case (5 July 1980) was considered valid at 0000 UTC on day +1 .
For example, the valid time of the 3 May 1999 tornado outbreak was 0000 UTC 4 May 1999. Because the valid time of the 5 July 1980 PNO did not match the valid times of any of the other outbreak cases, it was excluded from the study.

\section{b. The initial dataset}

The data used for the initialization of the model runs were the National Centers for Environmental PredictionNational Center for Atmospheric Research (NCEPNCAR) reanalysis datasets (Kalnay et al. 1996). These datasets are available at 0000, 0600, 1200, and 1800 UTC each day from 1948 to the present. The reanalysis output has a horizontal grid spacing of $2.5^{\circ}$ latitude by

TABLE 2. As in Table 1, but for the 50 PNOs.

\begin{tabular}{|c|c|c|}
\hline 2 Jul 1980 VH/VH/VH & 4 Jul 1985 VH/VH/ $\boldsymbol{V H}$ & 18 May $1996 \mathrm{VH} / V H^{*} / V H^{*}$ \\
\hline 5 Jul 1980 Excluded & $9 \mathrm{Jul} 1985 \mathrm{VH} / \mathrm{VH} / \mathrm{VH}$ & 20 Jun 1997 VH/VH/VH \\
\hline $8 \mathrm{Jul} 1980 \mathrm{VH} / V H^{*} / \mathrm{VH}$ & $10 \mathrm{Jul} 1985 \boldsymbol{H} / \boldsymbol{V H} / \mathrm{H}$ & $21 \mathrm{Jul} 1998 \mathrm{VH} / V H^{*} / V H^{*}$ \\
\hline $12 \mathrm{Jul} 1980 \mathrm{H} / \mathrm{H} / \mathrm{H}$ & 6 Aug 1985 VH/VH/VH & 22 May $1999 \boldsymbol{H} / \mathrm{VH} / \mathrm{VH}$ \\
\hline $16 \mathrm{Jul} 1980 \mathrm{VH} / \mathrm{H} / \mathrm{VH}$ & 6 May 1986 H/H/M & $21 \mathrm{Jul} 2000 \mathrm{H} / \boldsymbol{V H} / \mathrm{VH}$ \\
\hline 6 Aug 1980 VH/H/H & 1 Aug 1986 VH/VH/VH & 11 Sep 2000 H/H/H \\
\hline 28 Apr $1981 \mathrm{M} / \mathrm{H} / \mathrm{H}$ & 17 Jun 1987 VH/VH/VH & 9 Apr $2001 \mathrm{~L} / \mathrm{L} / \mathrm{L}$ \\
\hline 8 May $1981 \boldsymbol{H} / \mathrm{H} / \mathrm{H}$ & $5 \mathrm{Jul} 1987$ VH/H/H & $14 \mathrm{Apr} 2001 \mathrm{M} / \mathrm{H} / \mathrm{VH}$ \\
\hline 8 Jun 1982 H/H/H & 21 May 1989 VH/M/VH & 14 Jun $2001 \mathrm{M} / \mathrm{M} / \mathrm{H}$ \\
\hline 3 Aug 1982 VH/VH/H & 5 Aug $1989 \mathrm{VH} / \mathrm{VH} / \mathrm{VH}$ & 2 May 2002 L/L/L \\
\hline 4 Jul 1983 H/H/H & $20 \operatorname{Nov} 1989 L * / L * / L^{*}$ & 15 Jun $2002 \mathrm{VH} / \boldsymbol{V H} / \mathrm{VH}$ \\
\hline 19 Jul $1983 \boldsymbol{V H} / V H^{*} / V H^{*}$ & 16 Apr 1990 VH/VH/L & 16 Aug 2002 M/VH/VH \\
\hline $29 \mathrm{Aug} 1983 \mathrm{VH} / \mathrm{VH} / V H^{*}$ & $4 \mathrm{Jul} 1992 \mathrm{VH} / \mathrm{VH} / V H^{*}$ & 2 May $2003 V H^{*} / \mathrm{VH} / \mathrm{VH}$ \\
\hline 12 May $1985 \boldsymbol{V H} / V H^{*} / \mathrm{VH}$ & 12 Oct $1993 \boldsymbol{H} / \mathrm{VH} / \mathrm{H}$ & $7 \mathrm{Jul} 2003 \mathrm{H} / \mathrm{VH} / \mathrm{H}$ \\
\hline 4 Jun 1985 VH/VH/VH & 10 Apr $1994 \mathrm{~L} / \boldsymbol{L} / \mathrm{L}$ & \\
\hline 5 Jun 1985 VH/H/H & $15 \mathrm{Jul} 1995 \mathrm{VH} / \mathrm{VH} / \mathrm{H}$ & \\
\hline 7 Jun 1985 H/H/H & $25 \mathrm{Jul} 1995 \mathrm{VH} / \mathrm{VH} / \mathrm{VH}$ & \\
\hline 24 Jun $1985 \mathrm{VH} / \boldsymbol{V H} / \boldsymbol{V H}$ & 5 May 1996 M/H/M & \\
\hline
\end{tabular}




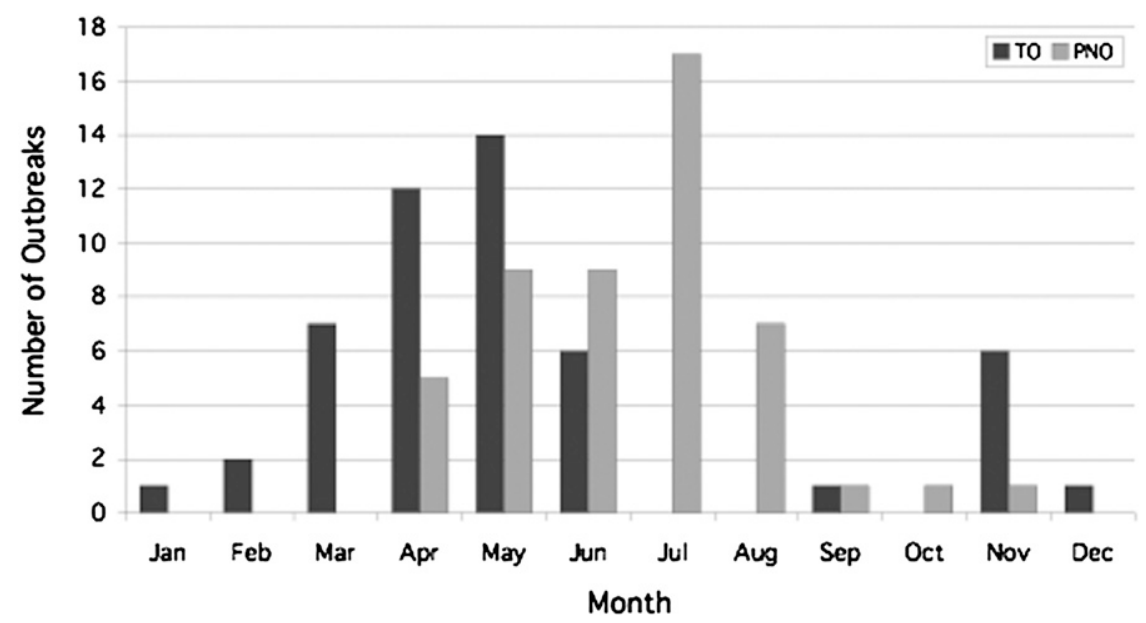

FIG. 1. Number of tornadic and primarily nontornadic outbreaks by month used in this study.

longitude (corresponding roughly to $200-225 \mathrm{~km}$ ). There are 17 vertical levels. To produce these datasets, data assimilation is performed using a spectral statistical interpolation technique (Derber et al. 1991; Parrish and Derber 1992), quality control of rawinsonde data based on Collins and Gandin (1990, 1992), optimal interpolation-based quality control (OIQC) of other data (Woollen 1991; Woollen et al. 1994), optimal interpolation of sea surface temperature (SST) reanalysis (Reynolds and Smith 1994), and a one-way coupled ocean model (Ji et al. 1994). NCEP-NCAR reanalysis incorporates the use of a T62/28-level NCEP global spectral model for data assimilation. The vertical structure generally contains five levels in the boundary layer (for reasonable resolution of this layer) and is increasingly stretched with height. The model is described fully in Kanamitsu (1989) and Kanamitsu et al. (1991), with details regarding model physics and dynamics included.

The process of OIQC in the development of NCEPNCAR reanalysis data results in the removal of any data considered grossly erroneous (whether by instrumentation error, human error, communication problems, etc.) and observations containing "large errors of representativeness that are accurate but whose measurements represent spatial and temporal scales impossible to resolve properly in the analysis-forecast system" (Kalnay et al. 1996, 446-447). Since this dataset consists of horizontal and vertical grid spacings consistent with the synoptic scale (e.g., Orlanski 1975; Holton 1992), this procedure satisfies our requirement to minimize subsynoptic-scale features from the model input. Moreover, this dataset covers analyses from 1948 to the present, which allowed the consideration of a large number of cases. This is important in tornado outbreak studies, given that these are rare events, necessitating a long pe- riod of record to be used in order to have a sufficiently large sample (Doswell 2007b) to draw meaningful conclusions.

\section{c. The mesoscale model}

The Weather Research and Forecasting (WRF) mesoscale model, version 2.1.2, (Skamarock et al. 2005) was chosen for this project. The WRF uses a fully compressible, nonhydrostatic dynamical core. The horizontal grid uses Arakawa-C staggering, and the vertical coordinate is a terrain-following hydrostatic-pressure parameter. Time integration uses a third-order RungeKutta scheme with appropriately small time steps for acoustic and gravity waves and is described in Wicker and Skamarock (2002). Lateral boundary conditions were implemented using the NCEP-NCAR reanalysis datasets at the appropriate times. The model top was $50 \mathrm{hPa}$

Each simulation consisted of five domains (Fig. 3). The outermost domain (D01) was fixed, used grid spacing of $162 \mathrm{~km}$ with dimensions of $70 \times 35(x$ and $y$ directions, respectively), and was centered at $40^{\circ} \mathrm{N}$ and $100^{\circ} \mathrm{W}$. The second domain (D02) used grid spacing of $54 \mathrm{~km}$ with dimensions of $100 \times 70$ and was also fixed for each run. Domain 3 (D03) used grid spacing of $18 \mathrm{~km}$ with dimensions of $121 \times 121$ and was translated according to the general location of an outbreak on its relevant day. This positioning was performed manually and was based on the severe reports as plotted on the Storm Prediction Center's (SPC) software package called SVRPLOT (Hart 1993). Domain 4 (D04) used grid spacing of $6 \mathrm{~km}$ with dimensions of $202 \times 202$ and was also translated in the same manner as for domain 3. Domain 5 (D05) used grid spacing of $2 \mathrm{~km}$ with dimensions of $502 \times 502$ and 
a)

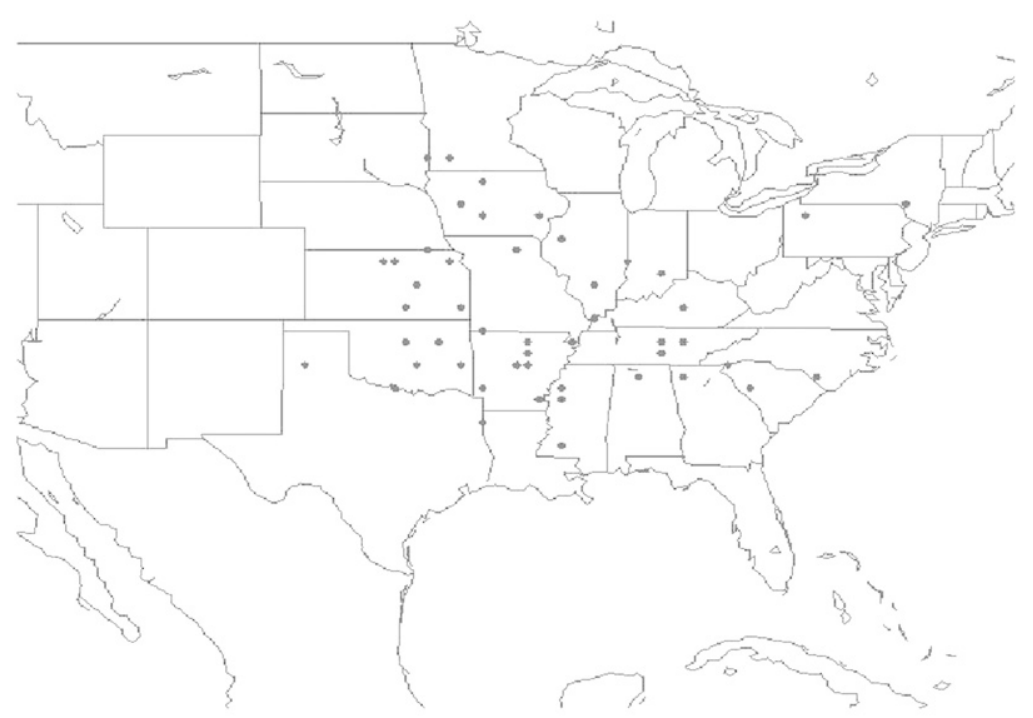

b)

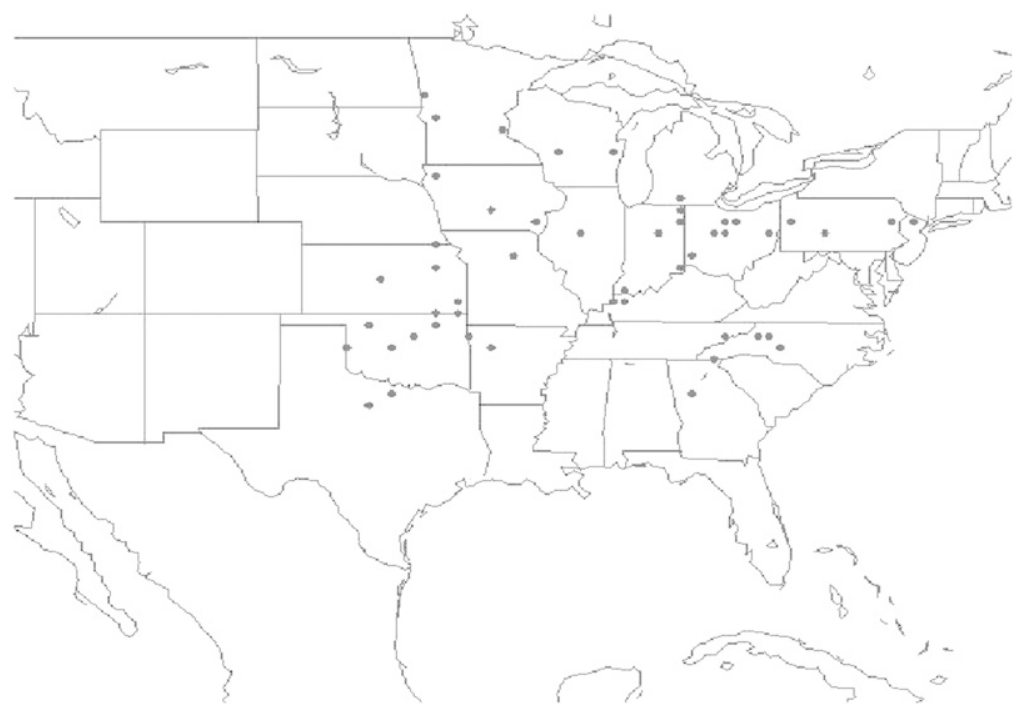

FIG. 2. Approximate centers of the (a) TOs and (b) PNOs used in this study. Two outbreak centers overlap for TOs, leaving 48 points. One outbreak center overlaps for PNOs, leaving 49 points.

was fixed (relative to D04) for each run. There were 31 vertical levels for each domain. Two-way nesting (Skamarock et al. 2005) was used for each simulation.

The model physical schemes used in the simulations (Table 3) were selected, and others were eliminated, based on theoretical assumptions or initial experimentation. For example, the WRF Single-Moment 6-class (WSM6) microphysics scheme was selected because it includes graupel and its associated processes, which is necessary for simulating convection at scales for which deep convection is explicit (Skamarock et al. 2005).

\section{d. The methodology}

Each outbreak case was simulated for 1-, 2-, and 3-day forecasts for a total of 300 simulations. These forecast periods were chosen to investigate the trends over a 3-day window in the ability of the WRF to distinguish outbreak type and provide qualitative and quantitative evidence into the degree of synoptic-scale involvement influencing the occurrence of tornado outbreaks during this temporal window.

The model output was analyzed subjectively. Although objective analysis of these cases is currently under way 


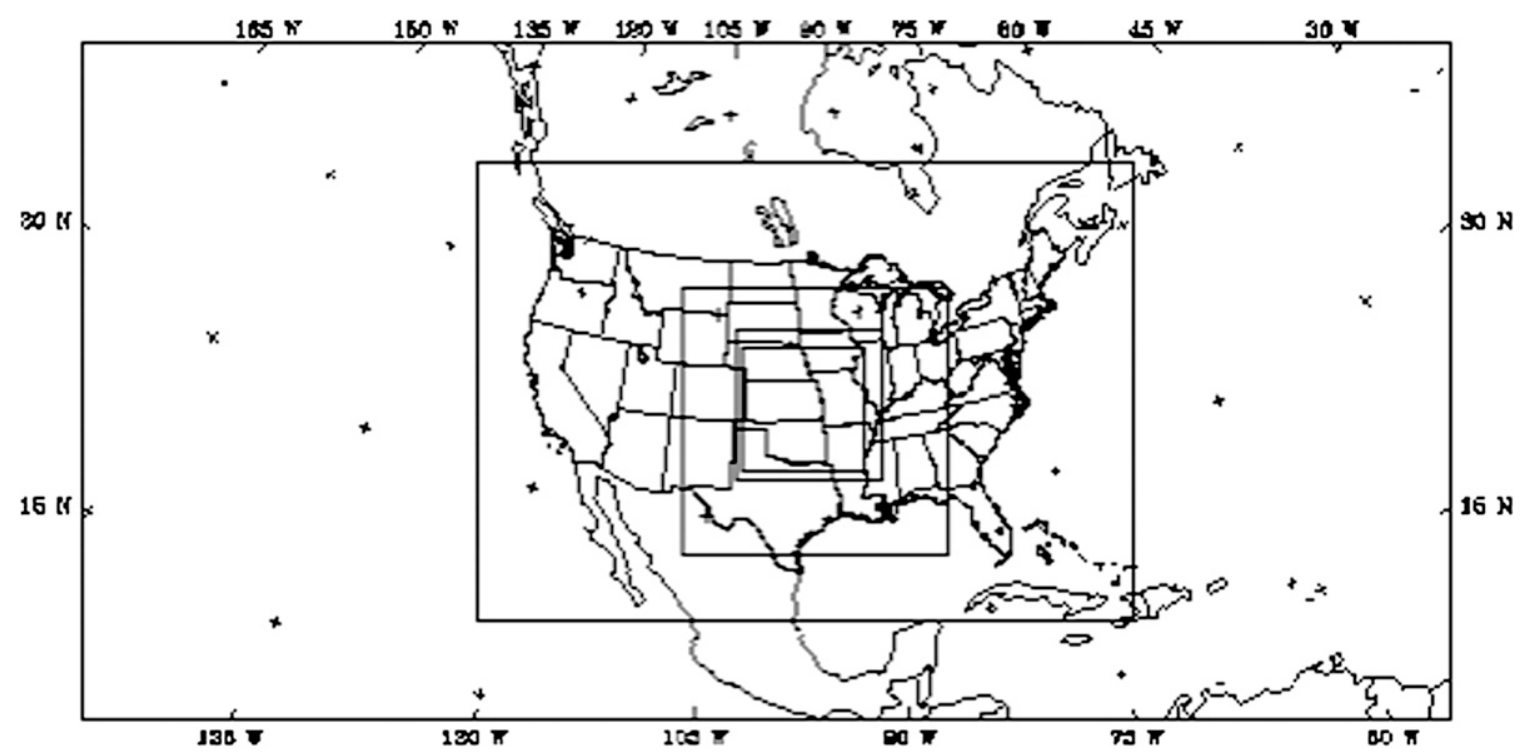

FIG. 3. Sample domain setup for WRF simulations. This example was used for the 3 May 1999 TO simulations.

and is essential to complete a determination of the WRF's ability to distinguish outbreak type (see section 5), a subjective analysis was useful for several reasons. It can be combined with objective techniques to ensure a more complete understanding of the model's ability to discriminate TOs from PNOs. Similar analysis has been conducted in previous studies (e.g., Jankov et al. 2005). Subjective analysis can explain why objective techniques succeed in some circumstances and fail in others (e.g., SCB97); similarly, it can be used to improve the methodologies used in objective analysis (see section 4). Finally, subjective analysis of these simulations can be a good way to evaluate the performance of objective techniques, as it provides an estimate of how well objective techniques should perform for these simulations.

Because it is not feasible to resolve tornadoes explicitly in a mesoscale model given the scope of this project, meteorological covariates (Brown and Murphy 1996) were analyzed to determine if the model was predicting the correct type of outbreak. In our study, these meteorological covariates were severe-weather parameters that can be resolved by the mesoscale model and have been shown to be associated with tornadoes (e.g., Davies-Jones et al. 1990; Davies and Johns 1993; Droegemeier et al. 1993; Johns et al. 1993; Brooks et al. 1994a,b). Previous work focused on using severeweather parameters to distinguish tornadic from nontornadic storms, supercells from other storm types, significant severe storms from less significant severe storms, etc., using observed or model-derived sounding data (e.g., Rasmussen and Blanchard 1998; Craven et al. 2002a,b; Doswell and Evans 2003; Thompson et al. 2003), reanalysis data (e.g., Brooks et al. 2003b), or model forecast severe parameters (e.g., SCB97). Because the focus here was on distinguishing TOs from PNOs, both of which may and often do consist of supercells, the convective mode was not considered in distinguishing outbreak type (see section 4f).

After an analysis of more than 20 severe-weather parameters for each simulation, a list of the parameters

TABLE 3. Model physical schemes used for this study.

\begin{tabular}{ll}
\hline \multicolumn{1}{c}{ Model physics } & \multicolumn{1}{c}{ References } \\
\hline WSM6 microphysics & Lin et al. (1983), Dudhia (1989), Hong et al. (1998), \\
& Skamarock et al. (2005) \\
Grell-Devenyi convective scheme; not used for D04 and D05 & Grell and Devenyi (2002) \\
Yonsei University planetary boundary layer scheme & Hong and Pan (1996) \\
MM5-derived surface layer scheme & Skamarock et al. (2005) \\
Five-layer thermal diffusion land surface model & Skamarock et al. (2005) \\
Rapid radiative transfer model for longwave radiation & Mlawer et al. (1997) \\
Dudhia shortwave radiation scheme & Dudhia (1989)
\end{tabular}


TABLE 4. Severe parameters analyzed in each WRF forecast. The magnitudes of the parameters indicate the general threshold values/ ranges to discriminate outbreak types. Values above the thresholds for all parameters but LCL indicate values commonly found in TOs. (Values below the LCL threshold were those commonly found in TOs.)

\begin{tabular}{lll}
\hline \hline \multicolumn{1}{c}{ Severe parameter } & \multicolumn{1}{c}{ Magnitudes } & \multicolumn{1}{c}{ References } \\
\hline LCL & $1000 \mathrm{~m} \mathrm{AGL}$ & Rasmussen and Blanchard (1998) \\
$0-1-, 0-3-$, and 0-6-km bulk shear & $10-15,25-30$, and 40-45 kt & Bunkers (2002) \\
0-1- and 0-3-km SREH & 150 and $250 \mathrm{~m}^{2} \mathrm{~s}^{-2}$ & $\begin{array}{c}\text { Davies-Jones et al. (1990), Davies and } \\
\text { Johns (1993), and storm motions } \\
\text { based on Maddox (1976) }\end{array}$ \\
0-1- and 0-3-km EHI & & Hart and Korotky (1991) \\
BRNSHR & $2-3$ and 3-5 & Droegemeier et al. (1993) \\
SRFL $\sim 2 \mathrm{~km}$ AGL & $30-40 \mathrm{~m} \mathrm{~s}^{2-2}$ & Kerr and Darkow (1996) \\
\hline
\end{tabular}

most helpful in distinguishing outbreak type and the approximate magnitudes to discriminate outbreak types was obtained (Table 4). Most of the parameters were vertical shear [i.e., the bulk shear and the Bulk Richardson number shear (BRNSHR)] or storm-relative [i.e., storm-relative environmental helicity (SREH) and storm-relative flow (SRFL)] variables. Additionally, the energy helicity index (EHI) and lifting condensation level (LCL) were also found to be helpful in the discrimination of outbreak types. The selection of these parameters is consistent with results of previous studies (Droegemeier et al. 1993; Johns et al. 1993; SCB97; Rasmussen and Blanchard 1998; Brooks et al. 2003b; Doswell and Evans 2003; Thompson et al. 2003). The severe-weather parameters in Table 4 should not be interpreted as those that are the best discriminators of all severe-weather parameters. The goal of this study is not to find the best discriminators; instead, the goal is to determine the ability of the model to distinguish outbreak type based on the forecast of severe-weather parameters known to be associated with tornadoes and significant severe weather. Furthermore, this study focuses on comparing severe-weather outbreak environments rather than individual storm environments (such as comparing tornadic supercells with nontornadic supercells). Therefore, direct comparison of the results of this study to proximity sounding studies is not recommended.

Each forecast was placed in one of four categories. The procedure for case classification was straightforward. Every severe-weather parameter in Table 4 was analyzed individually for each case. The magnitudes for every parameter were analyzed using the values listed in Table 4 to distinguish the outbreak types. For all parameters except LCL, larger values than those found in Table 4 signified TOs. The analysis of spatial structure included the areal coverage of the severe parameter (in relation to the size of the outbreak). For example, a TO with forecast $0-1-\mathrm{km}$ SREH above $150 \mathrm{~m}^{2} \mathrm{~s}^{-2}$ in a small area relative to the size of the actual outbreak would not be considered "proper discrimination." However, a TO with very high $0-1-\mathrm{km}$ SREH in a region approximately the size of (or larger than) the outbreak would be considered a correct discrimination.

Based on the forecast magnitude and spatial structure of the parameter, the forecast parameter was labeled " 1 " for proper discrimination and " 0 " otherwise. These values were summed up for the 10 parameters from each case, and classifications were designated based on this sum. A very high $(\mathrm{VH})$ classification indicated that at least eight severe-weather parameters favored the correct type of outbreak. A high $(\mathrm{H})$ classification meant that six to eight of the severe-weather parameters favored the correct type of outbreak. A medium (M) classification indicated that four to six of the severe parameters favored the correct type of outbreak. A low (L) classification meant that the majority of severe parameters favored the wrong type of outbreak. Some overlap for the categorizations was allowed because some of the variables are undoubtedly related (e.g., 0-1and $0-3-\mathrm{km}$ SREH), and these associations might interfere with a more appropriate classification. For example, a case in which every parameter except 0-1- and 0-3-km SREH favored the correct type of outbreak would be labeled $\mathrm{VH}$ rather than $\mathrm{H}$.

\section{Results}

In at least $70 \%$ of the cases for each forecast period, the selected individual severe-weather parameters could be used to distinguish outbreak type correctly with an even higher percentage discriminated correctly $(\sim 80 \%)$ when these parameters were analyzed in combination (Table 5). Convective available potential energy (CAPE; e.g., SCB97), convective inhibition (CIN; Colby 1984), the level of free convection (LFC), and vorticity generation potential (VGP; e.g., Rasmussen and Blanchard 1998) generally were not found to be 
TABLE 5. Number of forecasts for each outbreak type (i.e., TO or PNO) and for each category (i.e., $\mathrm{VH}, \mathrm{H}, \mathrm{M}$, and L) for each forecast period. Classifications based on analyses at the valid time of the outbreak (0000 UTC) and only in the region where the outbreak actually occurred.

\begin{tabular}{lccc}
\hline \hline Forecast type & 1 day & 2 day & 3 day \\
\hline TO-VH & 28 & 24 & 22 \\
TO-H & 15 & 17 & 22 \\
TO-M & 4 & 3 & 2 \\
TO-L & 3 & 6 & 4 \\
PNO-VH & 28 & 29 & 26 \\
PNO-H & 12 & 14 & 16 \\
PNO-M & 5 & 2 & 2 \\
PNO-L & 4 & 4 & 5 \\
\hline
\end{tabular}

helpful in the discrimination of outbreak type and were not used when classifying each case. For example, CAPE was present in all but one case (20 November 1989), but the forecast magnitudes and spatial structures were not associated clearly with outbreak type. A discussion regarding the inability of several thermodynamic instability parameters to aid in outbreak discrimination will be given in section 4 .

A comparison of the 2 June 1990 TO (Figs. 4a and 6) with the 20 June 1997 PNO (Figs. 5a and 7) indicated that $0-1-\mathrm{km}$ SREH and LCL are distinct in terms of both magnitudes and spatial structures. [In this analysis and those that follow, the tornado reports for the TOs (Fig. 4) and all severe reports for the PNOs (Fig. 5) are provided.] In the TO simulation, 0-1-km SREH (Fig. 6a) was very high (exceeding $300 \mathrm{~m}^{2} \mathrm{~s}^{-2}$ in much of Illinois and Indiana) along and ahead of an approaching cold front (Fig. 6d). LCLs were below $1000 \mathrm{~m}$ above ground level (AGL) in much of the warm sector (Fig. 6b). A 500-hPa low was located in the northern plains with strong southwesterly flow $\left(>35 \mathrm{~m} \mathrm{~s}^{-1}\right.$ ) approaching Illinois (Fig. 6c). In the PNO simulation, 0-1-km SREH was much weaker (generally well below $200 \mathrm{~m}^{2} \mathrm{~s}^{-2}$ ) and encompassed less area than in the TO simulation (Fig. 7a). LCLs were higher in the PNO simulation (generally above $1000 \mathrm{~m}$ AGL; Fig. 7b). Both 0-1-km SREH and LCLs were highest in an east-west corridor in northern Iowa, southern South Dakota, and southern Minnesota, associated with a warm front (Fig. 7d) below generally zonal 500-hPa flow parallel to the surface boundary (Fig. 7c).

This comparison illustrates two main results found when analyzing the simulations. First, in general, TO simulations featured more favorable parameters encompassing a much larger area than in PNO simulations. This implies that both the magnitudes and the spatial structures of the severe parameters were important for distinguishing outbreak type, particularly for outbreaks during the spring, when the magnitudes of many of the severe-weather parameters were similar for TOs and PNOs (e.g., Fig. 8). In these cases, visually assessing the spatial structure of the parameters was critical for correct diagnosis of outbreak type (e.g., Fig. 9).

Second, similar synoptic patterns favored one type of outbreak. Miller (1972) presented five map types associated with tornado occurrence (available online at http://stinet.dtic.mil/cgi-bin/GetTRDoc?AD = AD744042 \&Location $=\mathrm{U} 2 \&$ doc $=$ GetTRDoc.pdf) and suggested some of these map types were associated with more isolated tornadoes (or none at all), whereas others frequently were associated with a large number of tornadoes. In our study, all TOs were similar in appearance to the type A (Fig. 12 in Miller 1972), type B (Fig. 13 in Miller 1972), or type D (Fig. 15 in Miller 1972) synoptic map types. The type B map type features strong southwest flow atop a cold front or dryline aligned in a direction containing a strong perpendicular component to the midlevel flow (e.g., Figs. 9a,c). Type A is similar to the type B pattern except without an accompanying surface low. The type D map features a cold upper-level low with a surface occluded front. In these situations, it is common for convection to develop along the occlusion (generally east of the surface low) where strong southwesterly flow is found in the midlevels (e.g., Fig. 10).

However, PNOs were commonly associated with the type C (Fig. 14 in Miller 1972) or type E (Fig. 16 in Miller 1972) map types. The type C map type features a quasi-stationary front with midlevel flow parallel to the surface boundary. The type E map type is similar, but a surface low is also present (with associated warm and cold fronts). In the type E map type, midlevel flow is parallel to the warm front (e.g., Fig. 7). Types $\mathrm{C}$ and $\mathrm{E}$ patterns tend to favor large hail and damaging winds rather than tornadoes because convection often develops where instability is weak, and instability is generally higher where shear and stronger synopticscale lift are weaker. Last, PNOs favored northwest flow in the midlevels atop a surface boundary positioned west to east or southwest to northeast, similar to the types $\mathrm{G}$ and $\mathrm{Q}$ map types discussed by Johns (1984).

The categorizations for each forecast based on how many of the severe-weather parameters favored the correct outbreak type for 1-, 2-, and 3-day forecasts (Tables 1,2, and 5) were first limited to analyzing only the region in which the outbreak actually occurred only at the valid time of 0000 UTC on day +1 . (As will be discussed in section 4 , accounting for phase errors and looking at the temporal evolution of simulated outbreaks can be important in some cases.) The results suggest three main findings. First, the number of $\mathrm{VH}$ and $\mathrm{H}$ classifications far outnumbered the number of $\mathrm{M}$ 

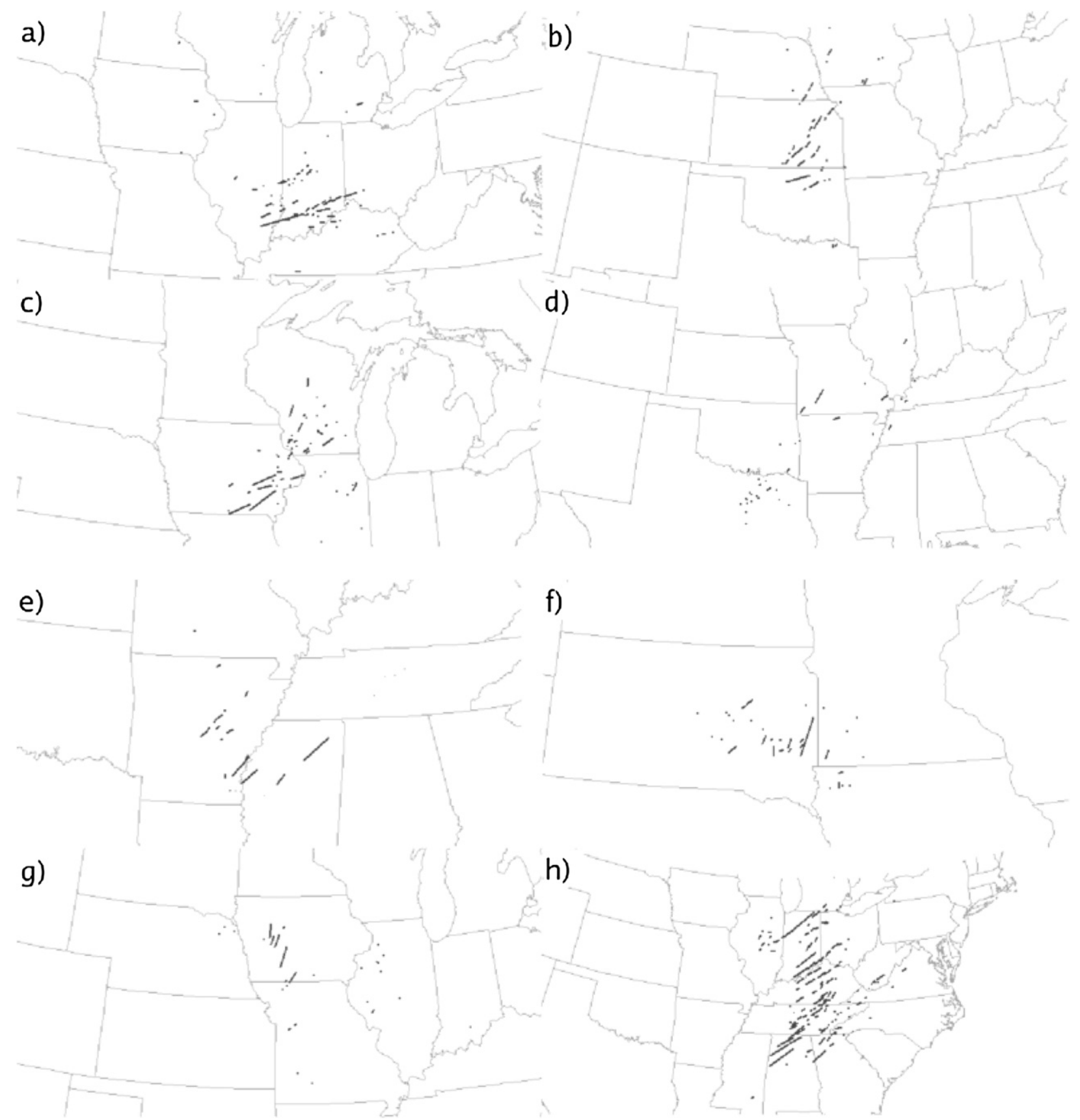

FIG. 4. Tornado reports as provided by the plotting program SVRPLOT for the (a) 2 Jun 1990 TO, (b) 26 Apr 1991 TO, (c) 8 May 1988 TO, and (d) 14 Dec 1971 TO, (e) 24 Feb 2001 TO, (f) 7 Jun 1993 TO, (g) 27 May 1995 TO, and (h) 3 Apr 1974 TO.

and L classifications. Generally, between 75 and $85 \%$ of TOs and PNOs were classified correctly by the severeweather parameters for all three forecast periods.

Second, the number of VH classifications decreased with a corresponding increase in $\mathrm{H}$ classifications as forecast length increased, especially for TOs. This is probable because of forecast degradation with increased forecast length (e.g., the number of cases with no simulated convection increased from 3 for 1-day forecasts to 11 for 3-day forecasts; refer to Tables 1 and 2). However, this trend was not as obvious with PNOs. Two factors were involved in this discrepancy. (i) Although forecasts degraded for the PNOs, these simulations generally did not trend toward predicting a tornado outbreak with 


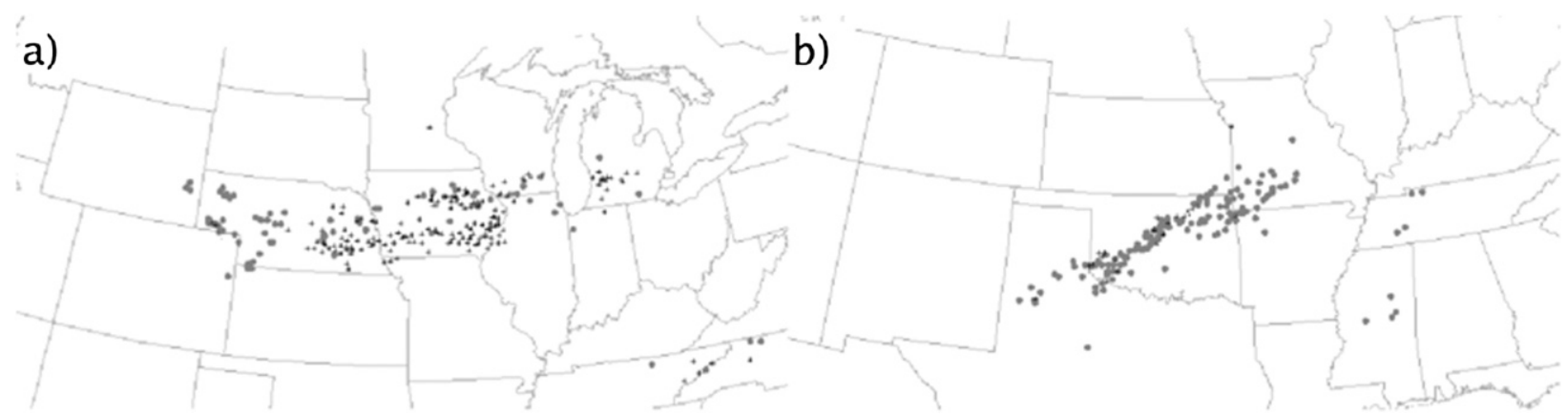

FIG. 5. All severe reports as provided by the plotting program SVRPLOT for the (a) 20 Jun 1997 PNO and (b) 10 Apr 1994 PNO.

an increase in forecast length, an expected result. (ii) The classification scheme was basically binary. If the forecast severe-weather parameters did not favor a tornado outbreak, it was classified as "null" (i.e., a forecast of no tornado outbreak). For PNOs, this was treated as a simulation that diagnosed outbreak type correctly whether or not a simulation was forecasting an outbreak at all. Because the null group covered any weather event that was not a tornado outbreak, it was more likely a case would be labeled as a PNO than a TO. This classification scheme assumed that if a TO was not forecast, the model was forecasting a PNO. This assumption was certainly not true in all cases, but was acceptable because the model's ability to predict whether an outbreak of severe weather will occur or not was beyond the scope of this study (refer to section 1).

Finally, classifications were reasonably consistent for a particular outbreak. Cases that favored the correct type of outbreak for 1-day forecasts usually did so for 3-day forecasts. Similarly, forecasts of the wrong type of outbreak for 1-day forecasts continued to diagnose poorly for 3-day forecasts. More specifically, 16 of the $28(57 \%)$ VH classifications for 1-day TO forecasts remained classified as $\mathrm{VH}$ for 2- and 3-day forecasts, and 20 of the $28(71 \%) \mathrm{VH}$ classifications for 1-day PNO forecasts remained so for 2- and 3-day forecasts. Similarly, TOs for which an M or L classification was given for any forecast period did not coincide with a $\mathrm{VH}$ classification for any other forecast period. TO (PNO) classifications were the same for $46 \%(61 \%)$ of the cases for each forecast period.

Given these results, the WRF appears capable of discriminating when outbreaks were primarily tornadic versus primarily nontornadic consistently at least 3 days in advance using only synoptic-scale input. This conclusion implies that synoptic-scale processes play a major role in these outbreaks. Furthermore, there is potential synoptic-scale predictability of TOs and PNOs several days prior to the outbreak.

\section{Potential complicating factors with discrimination of outbreak type}

\section{a. Thermodynamic instability parameters}

As mentioned in section 3, thermodynamic instability parameters were not found to be helpful in distinguishing outbreak type at lead times of 24-72 h. In particular, CAPE was found to be a poor discriminator for two reasons. First, when simulated convection develops in the model, the convection acts to remove the instability (as in the real atmosphere). Thus, if convection developed in the model before the valid time of the outbreak, CAPE was reduced substantially from the preconvective environment (Fig. 11).

Second, CAPE appeared to be strongly dependent on the time of year (Fig. 12). During cold-season tornado outbreaks (Figs. 12a,b), surface-based CAPE (SBCAPE) was generally quite low $\left(<1000 \mathrm{~J} \mathrm{~kg}^{-1}\right)$ in the warm sector. However, in the warm season, SBCAPE was much higher and was often comparable between TO and PNO simulations (Figs. 12c,d). This seasonal dependence overwhelmed any distinguishing power CAPE may have, which is consistent with previous studies (e.g., Johns et al. 1993). Brooks et al. (2003b) suggested CAPE may have more value in distinguishing significant severe weather from less significant severe thunderstorms.

There was one case in which SBCAPE shows value, whereas most of the other severe-weather parameters favored the wrong type of outbreak. In the 20 November 1989 PNO affecting portions of New York, Pennsylvania, and New Jersey, forecast low-level and deep-layer shear was very strong (not shown). However, SBCAPE was nonexistent in the Northeast. This case was very difficult to distinguish properly using the severe-weather parameters generally found to be most helpful in distinguishing outbreak type (refer to Table 2). However, if SBCAPE was required to be nonzero in the region of interest, this case would be classified properly. Nonzero SBCAPE was forecast in the observed outbreak regions of every TO 
a)

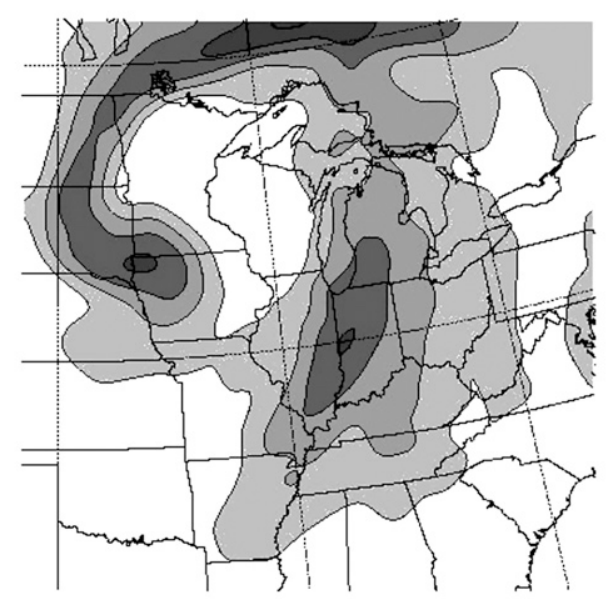

c)

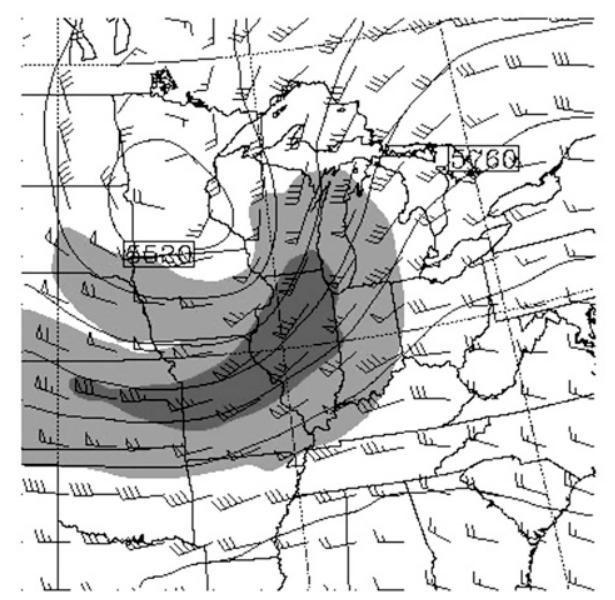

b)

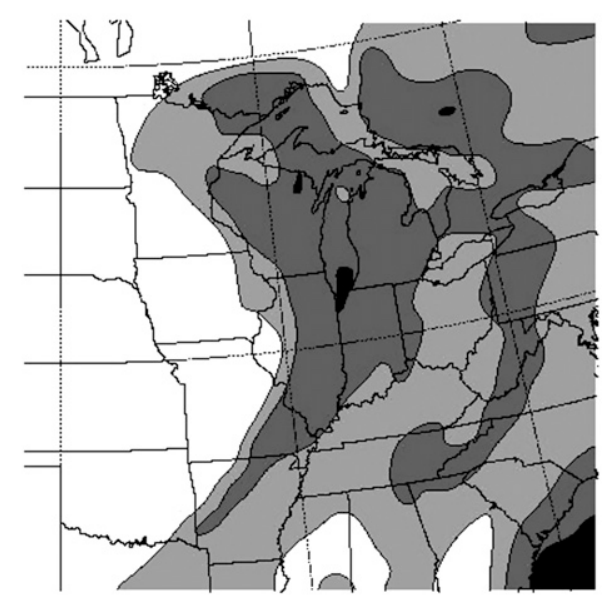

d)

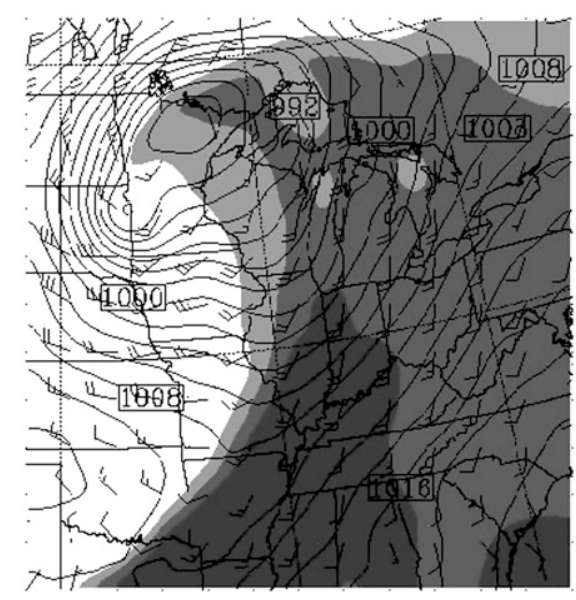

FIG. 6. One-day forecast of (a) 0-1-km SREH in $\mathrm{m}^{2} \mathrm{~s}^{-2}$ beginning at $100 \mathrm{~m}^{2} \mathrm{~s}^{-2}$ in increments of $100 \mathrm{~m}^{2} \mathrm{~s}^{-2}$; (b) LCL in $\mathrm{m}$ AGL beginning at $1500 \mathrm{~m}$ AGL in increments of $-500 \mathrm{~m} \mathrm{AGL}$; (c) 500-hPa wind speeds (filled contours beginning at $25 \mathrm{~m} \mathrm{~s}^{-1}$ in increments of $10 \mathrm{~m} \mathrm{~s}^{-1}$ ), geopotential height (contours; $\mathrm{m}$ ), and wind vectors (barbs; $\mathrm{kt}$ ); and (d) surface dewpoint temperatures (filled contours; ${ }^{\circ} \mathrm{C}$ beginning at $12^{\circ} \mathrm{C}$ in increments of $4^{\circ} \mathrm{C}$ ), mean sea level pressure (contours; hPa), and wind vectors (barbs; kt) for the 2 Jun 1990 TO valid at 0000 UTC 3 Jun 1990. Tornado reports for the 2 Jun 1990 TO can be found in Fig. 4a.

simulation, making a nonzero threshold appropriate for discrimination techniques. This result is consistent with findings by Monteverdi et al. (2003).

\section{b. Seasonal dependence}

Thermodynamic instability parameters are strongly tied to the time of year in which the outbreak occurs. This suggests the possibility that other severe-weather parameters could show seasonal dependence. Tables 1 and 2 lend credence to this possibility, as many PNOs difficult to distinguish from TOs occurred during the spring (e.g., 10 April 1994, 5 May 1996, 9 April 2001, and 2 May 2002). Furthermore, many TOs difficult to distinguish from
PNOs occurred in the late spring (e.g., 26 May 1973, 7 June 1984, 15 June 1992, 7 May 1993, and 6 May 2003). These events occurred when both types of outbreaks are common (refer to Fig. 1). However, PNOs primarily occurred during the summer when TOs are rarely observed, and many TOs occurred during the cold season, when PNOs are at a minimum. This finding suggests that the severe-weather parameters used to distinguish outbreak type might have a seasonal dependence.

A subjective analysis focused on TOs and PNOs occurring from 1 April to 16 June (Table 6) resulted in several findings. Most TOs more difficult to distinguish from PNOs feature relatively low values of shear (both 


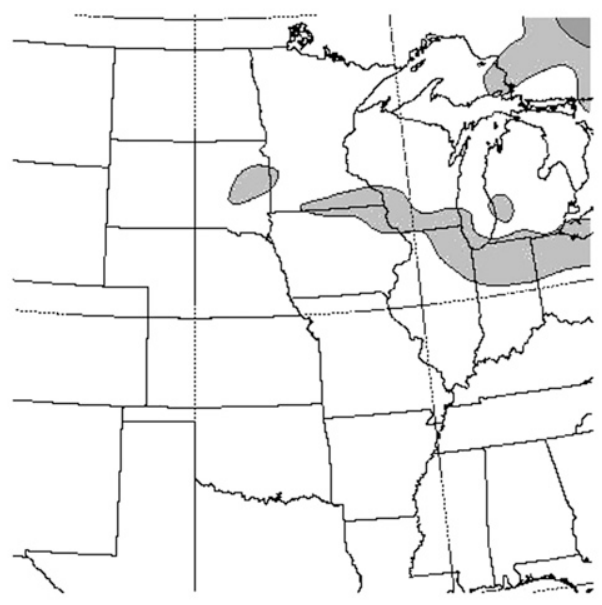

c)

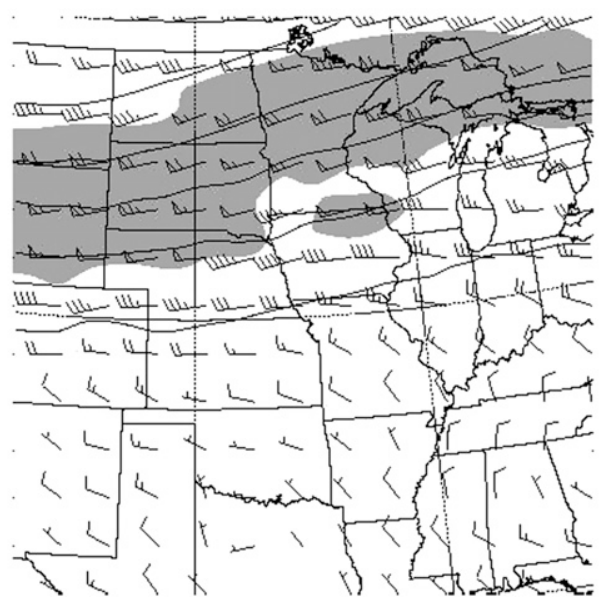

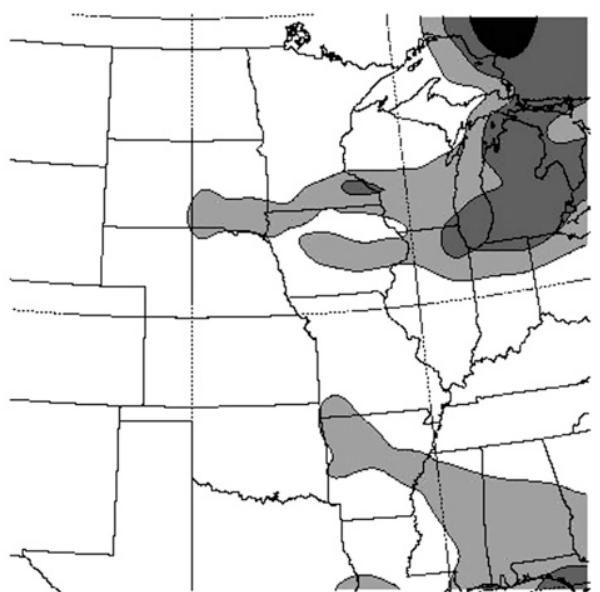

d)

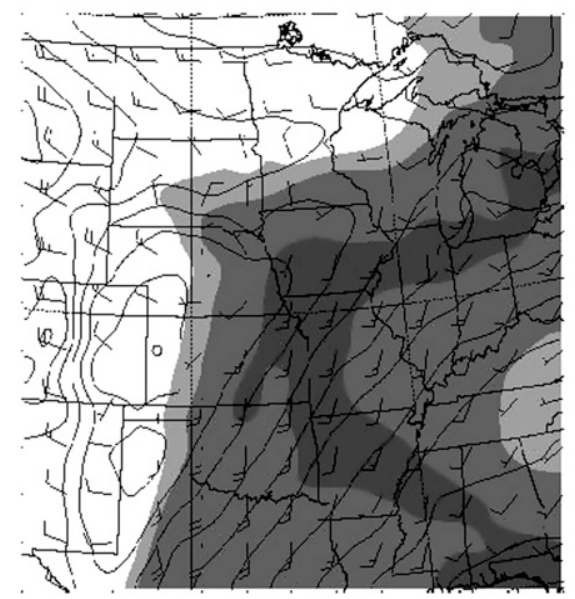

FIG. 7. As in Fig. 6, but for the 20 Jun 1997 PNO valid at 0000 UTC 21 Jun 1997. Severe reports for the 20 Jun 1997 PNO can be found in Fig. 5a.

low-level and deep-layer) and relatively high instability. Because most of the distinguishing variables are associated with vertical wind shear, this result is expected. Furthermore, these cases occurred in the late spring, when instability is higher and vertical shear is lower in the mean. Many of these cases were also susceptible to substantial underestimation of forecast severe parameters (e.g., 7 May 1993; see section 4d) or from dislocation of shear from instability (e.g., 27 May 1995; not shown). For late spring TOs, SREH, EHI, and SRFL tended to remain above the thresholds listed in Table 4, but bulk shear and LCL were less reliable.

Most forecast PNOs difficult to distinguish from TOs featured fewer "limiting factors" for the development of tornadoes than for PNOs occurring during the summer months. However, these cases commonly featured favor- able severe-weather parameters that were not collocated. For example, the 10 April 1994 PNO was predicted to have high instability and low LCLs in much of the warm sector (Fig. 8d), but relatively high SREH was forecast to the north of the warm sector (Fig. 8b). Similarly, the 2 May 2002 PNO was forecast to have strong low-level shear and instability in the warm sector, but strong deep-layer shear and storm-relative flow displaced to the north (not shown). In other cases (e.g., 28 April 1981), a small number of severe-weather parameters were well below the threshold values/ranges listed in Table 4. These variables were often 0-1-km SREH, 0-1-km EHI, and SRFL.

Most TOs and PNOs occurring outside the warm season could be distinguished by the type of pattern in place (refer to section 3) and by the strength of the associated shortwave troughs and flow fields. The TOs 
a)

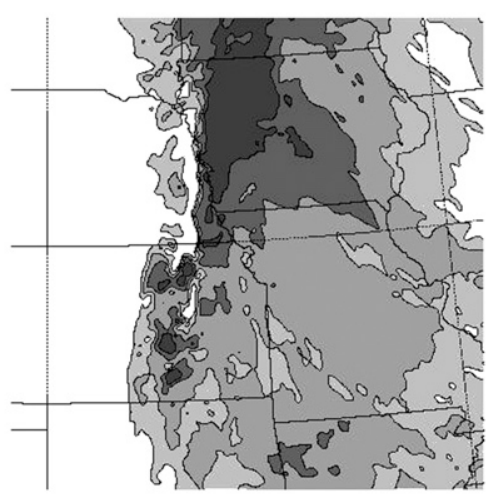

c)

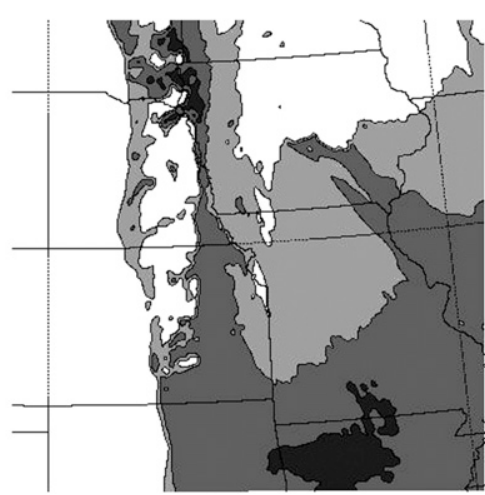

b)

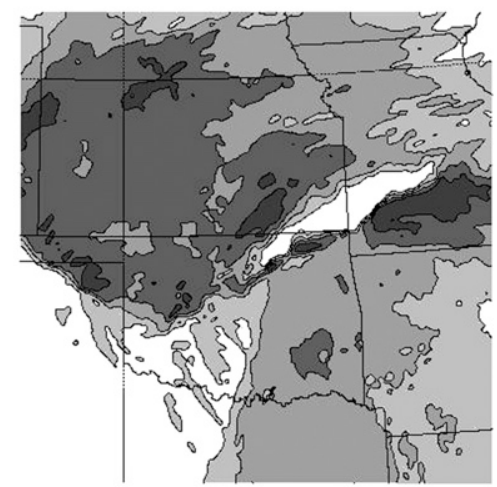

d)

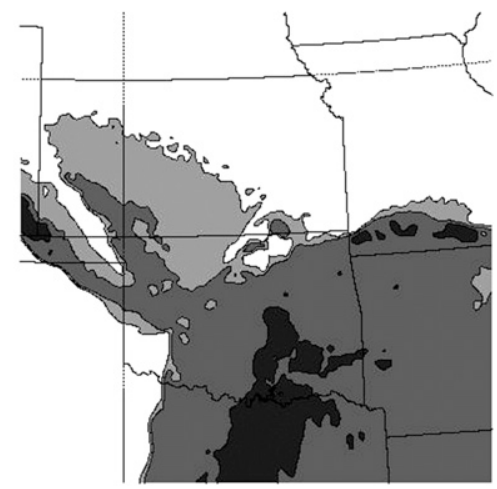

FIG. 8. One-day forecast of 0-1-km SREH $\left(\mathrm{m}^{2} \mathrm{~s}^{-2}\right.$ ) for the (a) $26 \mathrm{Apr} 1991 \mathrm{TO}$ valid at 0000 UTC 27 Apr 1991 and (b) 10 Apr 1994 PNO valid at 0000 UTC 11 Apr 1994, with shading as in Fig. 6a. One-day forecast LCL (m AGL) valid at (c) 0000 UTC 27 Apr 1991 and (d) 0000 UTC 11 Apr 1994 with shading as in Fig. 6b. Tornado reports for the 26 Apr 1991 TO can be found in Fig. 4b. Severe reports for the 10 Apr 1994 PNO can be found in Fig. 5b.

were primarily associated with amplified shortwave troughs with fast $\left(>30 \mathrm{~m} \mathrm{~s}^{-1}\right) 500-\mathrm{hPa}$ flow in a direction that crossed a surface boundary. PNOs were generally associated with weak, low-amplitude shortwave troughs with reduced 500-hPa wind speeds in a direction more parallel to a surface boundary.

Finally, there are 20 PNOs in our study during the 1 April-16 June period, which is much smaller than the 32 TOs that are included. Before more definitive conclusions can be drawn on the ability of the WRF to discriminate outbreaks appropriately using synoptic-scale input during the spring, a larger number of PNOs should be analyzed. Furthermore, the total number of cases analyzed during this span of time (i.e., 52) may not be large enough to draw meaningful conclusions (see Doswell 2007b).

\section{c. Regional dependence}

Despite the differences in the locations of TOs and PNOs (Fig. 2), little evidence was found to conclude that severe-weather parameters forecast in the WRF simulations were significantly different based on outbreak location. For example, the 8 April 1999 TO in the central plains and the 31 May 1985 TO in the Northeast look very similar for the 1-day forecast synoptic pattern (refer to Fig. 10), resulting in similar predictions for the magnitudes and spatial structures of severe-weather parameters (not shown). Although regional variations cannot be ruled out on the basis of our study (e.g., Johns 1984), any potential effects were overwhelmed by the time of year in which the outbreak occurs and the synoptic environment in place during the outbreak, which is also supported in previous studies (e.g., Johns et al. 1993; Brooks et al. 2003a; Coniglio and Stensrud 2004; Doswell et al. 2005; Horgan et al. 2007).

\section{d. Forecast accuracy versus discrimination}

The classifications of each case (see sections 2 and 3) were based on the actual outbreak location. However, 

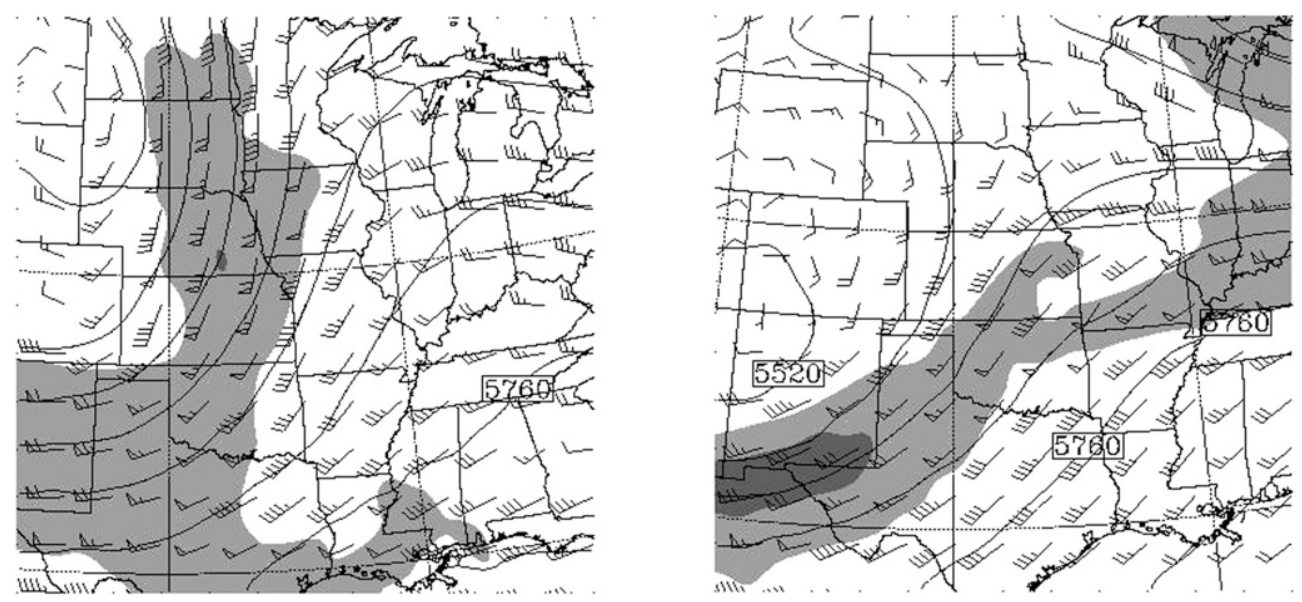

c)

d)
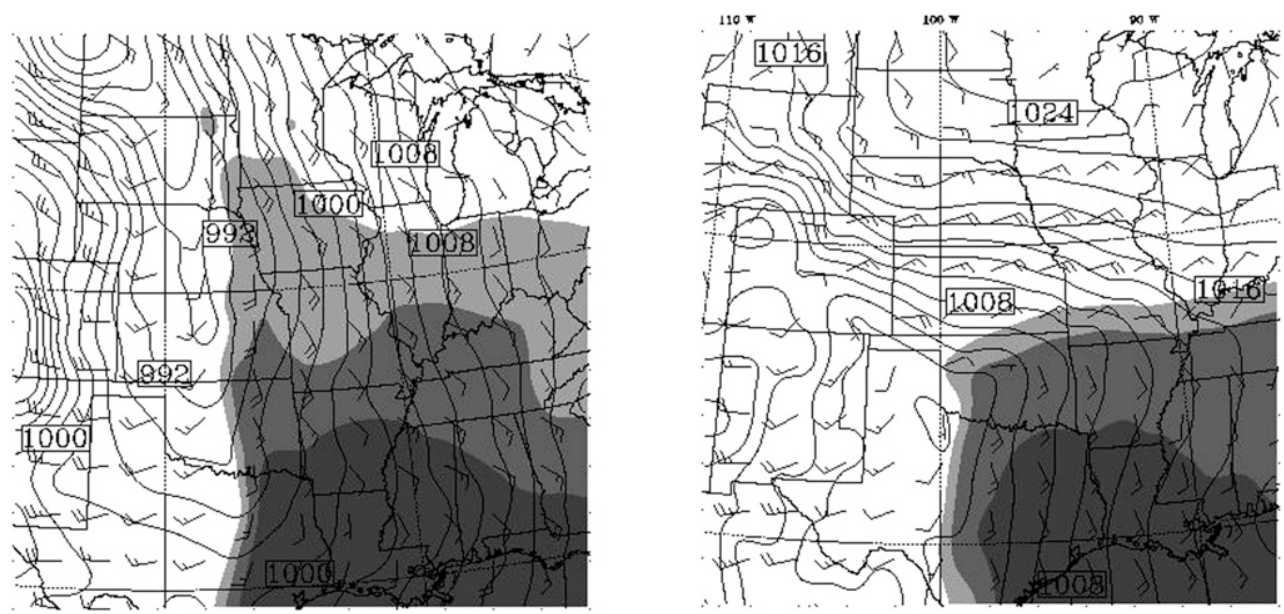

FIG. 9. One-day 500-hPa forecast (as in Fig. 6c) for the (a) 26 Apr 2001 TO valid at 0000 UTC 27 Apr 1991 and (b) 10 Apr 1994 PNO valid at 0000 UTC 11 Apr 1994. One-day surface forecast (as in Fig. 6d) valid at (c) 0000 UTC 27 Apr 1991 and (d) 0000 UTC 11 Apr 1994. Tornado reports for the 26 Apr 1991 TO can be found in Fig. 4b. Severe reports for the 10 Apr 1994 PNO can be found in Fig. 5b.

phase error in the model simulations may result in misclassification of a particular TO case when the model actually is suggesting a tornado outbreak, only in the wrong location. The 2-day forecast of the 17 April 1970 TO in the Texas Panhandle is one example (Fig. 13). At the valid time of the outbreak (0000 UTC 18 April 1970), the WRF simulated deep convection in Oklahoma, east of where the outbreak occurred. Based strictly at the location in which the outbreak actually occurred, the WRF showed little ability to distinguish outbreak type (i.e., high LCLs, weak low-level bulk shear, weak SREH). However, if the phase error was accounted for, correct discrimination of this case was easier. Forecast accuracy was not always associated with a model's inability to distinguish outbreak type.

Some TO simulations did not depict the magnitudes of the severe-weather parameters accurately, as determined by observed soundings (e.g., 7 May 1993 and 3 May 1999). In these situations, the correct discrimination of outbreak type was much more difficult (not shown). These two cases are examples of inaccurate model forecasts interfering with the correct diagnosis of outbreak type. (Another example is the 26 April 1991 TO; see Figs. 8a,c.) These model deficiencies (in terms of model or initial condition errors) cannot be accounted for in the classification of outbreak type using the method developed. 
a)

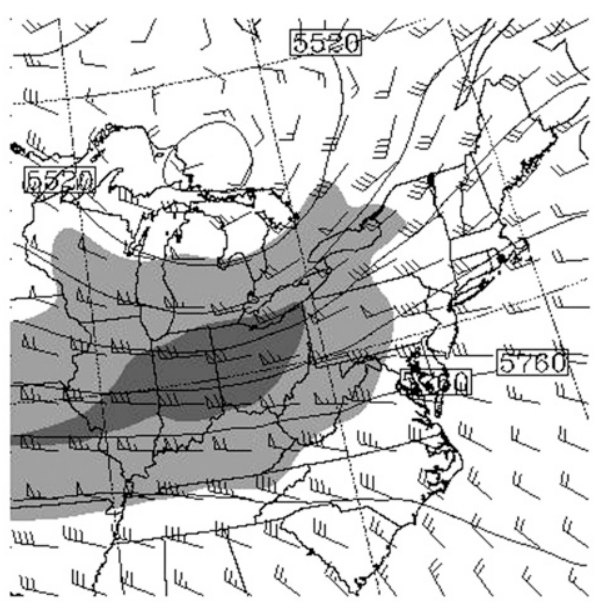

c)

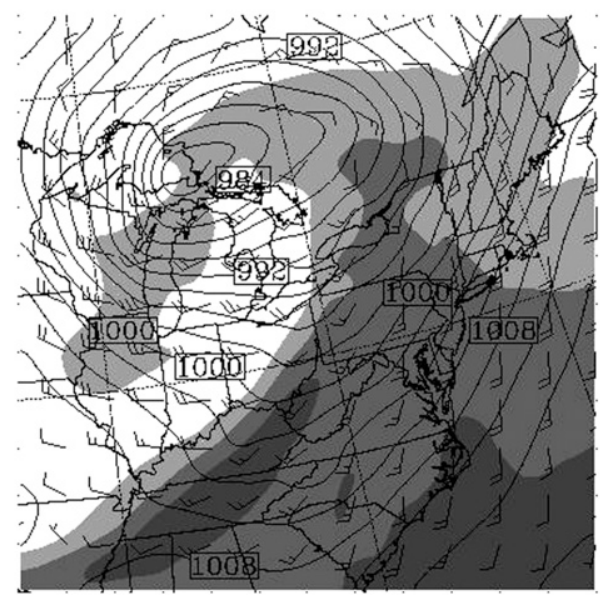

b)

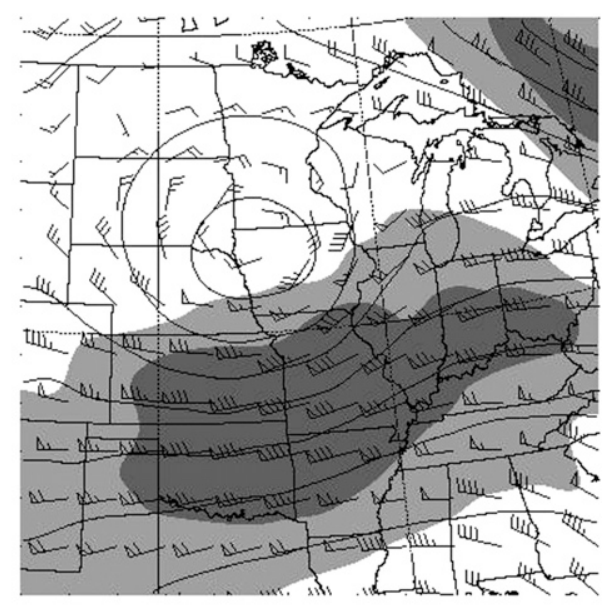

d)

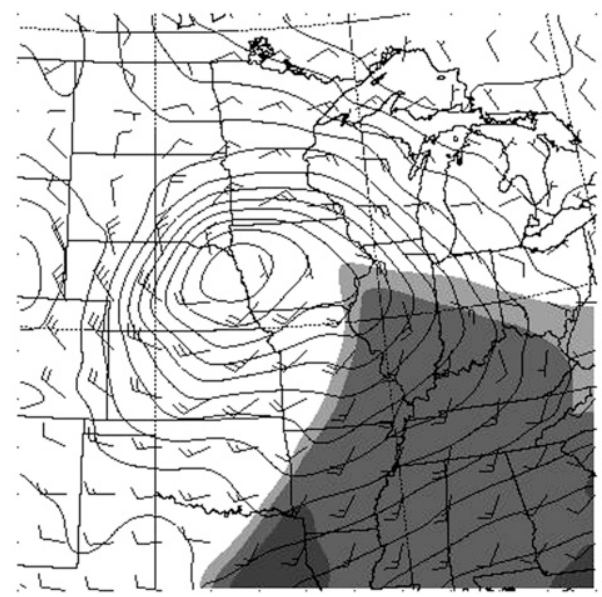

FIG. 10. One-day 500-hPa forecast (as in Fig. 6c) for the (a) 31 May 1985 TO valid at 0000 UTC 1 Jun 1985 and (b) 8 April 1999 TO valid at 0000 UTC 9 Apr 1999. One-day surface forecast (as in Fig. 6d) valid at (c) 0000 UTC 1 Jun 1985 and (d) 0000 UTC 9 Apr 1999.

\section{e. Temporal evolution}

Case classifications also were limited to the valid time of 0000 UTC on day +1 . However, each outbreak evolves over time (SCB97). For example, conditions may not become favorable for tornadoes until low-level shear is enhanced by the low-level jet stream (Stensrud 1996; Doswell and Bosart 2001) and the nocturnal boundary layer wind maximum (Blackadar 1957; Doswell and Bosart 2001). The model may simulate convection well before or after the valid time, implying the model's outbreak valid time is not the same as that designated for the classifications. If temporal evolution is not accounted for, misleading classifications can result.
To account for these discrepancies, a reclassification of the cases was conducted to include the effects of phase error and temporal evolution. The cases were analyzed from $6 \mathrm{~h}$ before to $6 \mathrm{~h}$ after the valid time of the outbreaks in 3-h intervals. A noticeable improvement in the classification of many TO simulations for 1- and 2-day simulations was observed (Tables 7 and 8). However, 3-day simulations showed less improvement, which is likely an indication that forecast degradation is counteracting any improvements from the revised classification scheme.

A reclassification of the PNOs accounting for these two factors resulted in no change in the classifications. This was a function of the forecast severe-weather parameters 


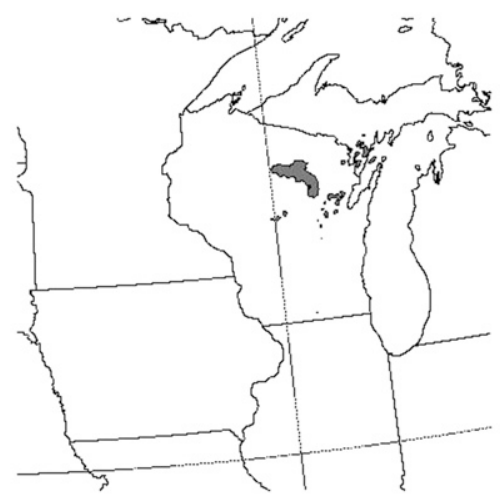

c)

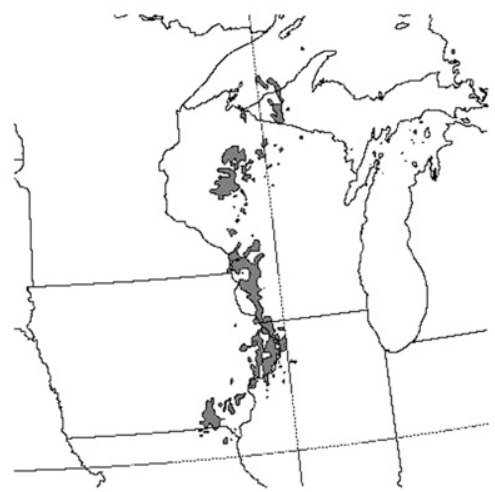

b)
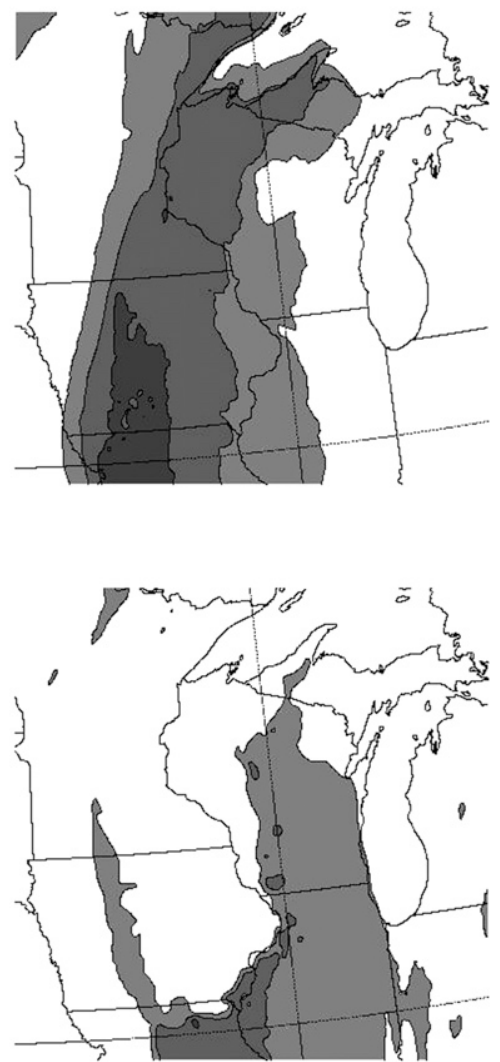

FIG. 11. Forecast of the 8 May 1999 TO initialized at 0000 UTC 8 May 1988 and valid at 1800 UTC 8 May 1988 for (a) radar reflectivity factor (shading above $40 \mathrm{dBZ}$ ) and (b) SBCAPE (light gray shading 500-1000 $\mathrm{J} \mathrm{kg}^{-1}$, medium gray shading $1000-3000 \mathrm{~J} \mathrm{~kg}^{-1}$, and dark gray shading $3000+\mathrm{J} \mathrm{kg}^{-1}$ ). (c) As in (a), but valid at 0000 UTC 9 May 1988. (d) As in (b), but valid at 0000 UTC 9 May 1988. Tornado reports for the 8 May 1988 TO can be found in Fig. 4c.

not favoring TOs. In some simulations, LCLs lowered and low-level shear increased when nocturnal cooling commenced and the low-level jet stream and nocturnal boundary layer wind maximum developed after the valid time. However, these increases were not significant enough to change the classifications of the cases.

\section{f. Simulated convection}

Analysis of simulated convection was not included in the process of classifying the cases. The use of a convective parameterization scheme at low grid spacings $(<10 \mathrm{~km})$ is controversial. (In this study, a convective parameterization was not incorporated for D04 and D05; see Table 3.) Convective parameterization schemes at these low grid spacings violate assumptions with which the schemes are developed (e.g., Molinari and Dudek 1992); however, some studies have shown better performance when a scheme is used at these fine scales (e.g., Deng and Stauffer 2006). Unfortunately, this makes the analysis of simulated convection somewhat problematic (see Brooks et al. 1992). Furthermore, although the convective mode often has implications on the type of severe weather that will occur (e.g., SCB97; Doswell and Evans 2003), the majority of supercells do not produce tornadoes (Moller 2001), suggesting that supercell forecasting is not the same as tornado forecasting (Johns and Doswell 1992).

However, the analysis of simulated convection did provide insight into the frequency with which models predicted convection for the outbreaks. The WRF did not develop simulated deep convection in every forecast (Tables 1,2, 9, and 10). There were three cases in which little or no convection was simulated for 1-day forecasts (3 May 1999, 20 November 1989, and 2 May 2003). For 3-day forecasts, 11 such cases emerged, a clear indication of forecast degradation from 1- to 3-day forecasts. Most of the forecasts in which little simulated convection developed were in the month of May (Tables 9 and 10). These simulations (26 May 1973, 
a)

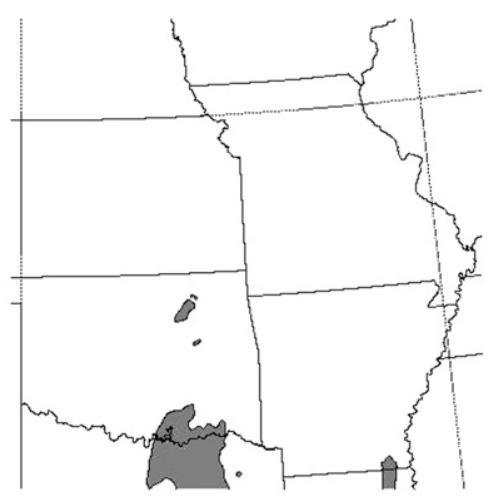

c)

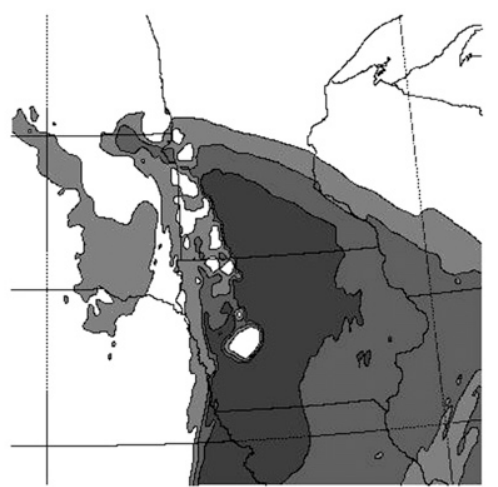

b)

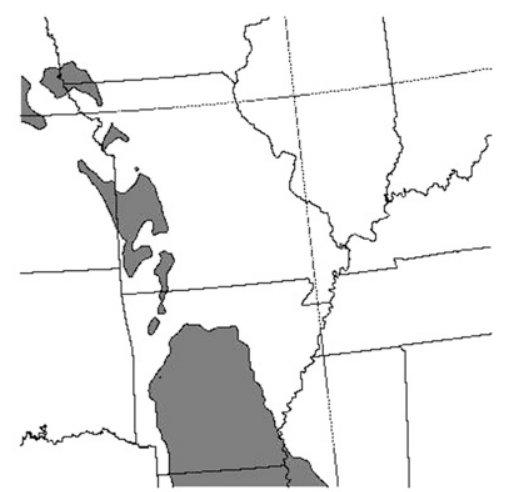

d)

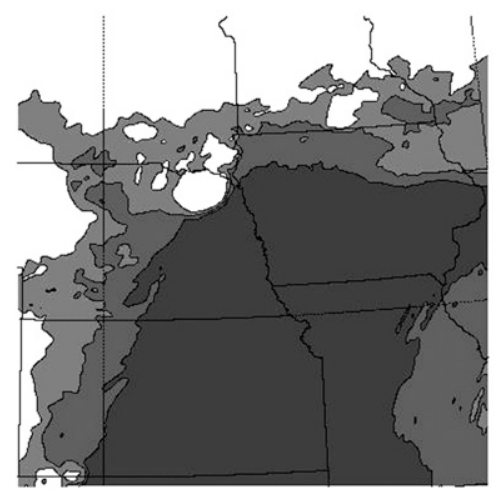

FIG. 12. One-day forecast SBCAPE ( $\mathrm{J} \mathrm{kg}^{-1}$ ) valid for the (a) $14 \mathrm{Dec} 1971 \mathrm{TO}$, (b) $24 \mathrm{Feb}$ 2001 TO, (c) 7 Jun 1993 TO, and (d) 20 Jun 1997 PNO. Shading as in Fig. 11b. Tornado reports can be found for the 14 Dec 1971 TO in Fig. 4d, the 24 Feb 2001 TO in Fig. 4e, and the 7 Jun 1993 TO in Fig. 4f. Severe reports for the 20 Jun 1997 PNO can be found in Fig. 5a.

7 May 1993, 18 May 1996, 3 May 1999, and 6 May 2003) were associated with substantially weaker shortwave troughs and less favorable severe-weather environments than observed. Some of the forecasts in which little simulated convection developed were PNOs during the warm season (e.g., 19 July 1983, 29 August 1983, 4 July 1992, and 21 July 1998; see Tables 2 and 10). These environments were characterized by high instability from strong heating and high CIN. Elevated mixed layers were common as dry air was advected eastward from the Desert Southwest, creating strong environmental capping stable layers.

Summertime PNO environments were also characterized by relatively quiescent (Igau and NielsenGammon 1998) environments on the synoptic scale. In contrast, TOs and PNOs during the spring and fall featured strong synoptic-scale systems with associated large-scale lift. These environments are generally forecast more accurately than warm-season, relatively quiescent environments (e.g., Stensrud and Fritsch 1994;
Baldwin et al. 2002). Model performance also is highly sensitive to initial conditions and the choice of model parameterizations (Stensrud and Fritsch 1994). The degradation in the prediction of deep convection is likely associated with these sensitivities.

Similarly, in nearly half the forecasts, simulated deep convection had a poleward bias, sometimes over $100 \mathrm{~km}$ from where most of the severe convection actually

TABLE 6. As in Table 5, but for outbreaks occurring between 1 Apr and 16 Jun only.

\begin{tabular}{lccc}
\hline \hline Forecast type & 1 day & 2 day & 3 day \\
\hline TO-VH & 11 & 10 & 8 \\
TO-H & 14 & 14 & 18 \\
TO-M & 4 & 3 & 2 \\
TO-L & 3 & 5 & 4 \\
PNO-VH & 8 & 8 & 8 \\
PNO-H & 5 & 7 & 6 \\
PNO-M & 4 & 2 & 2 \\
PNO-L & 3 & 3 & 4 \\
\hline
\end{tabular}




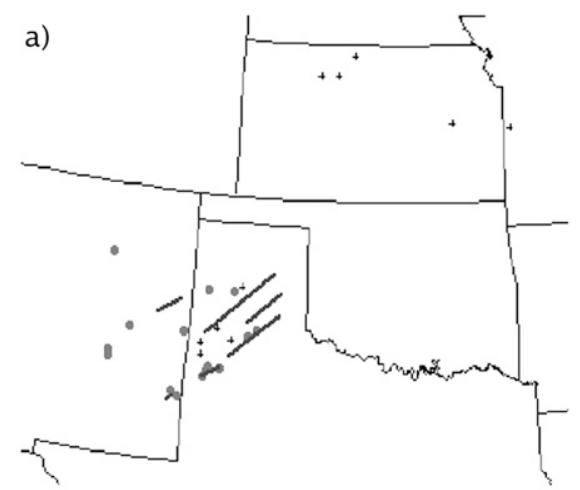

c)

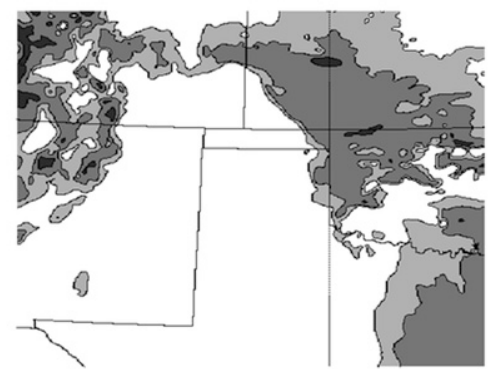

b)

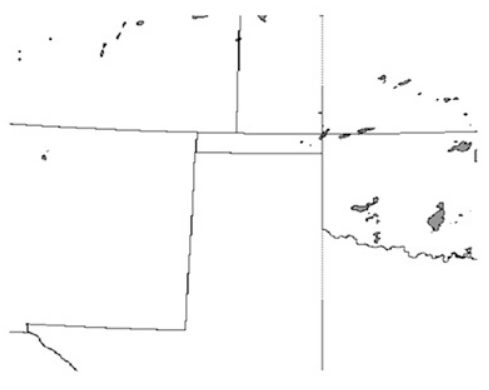

d)

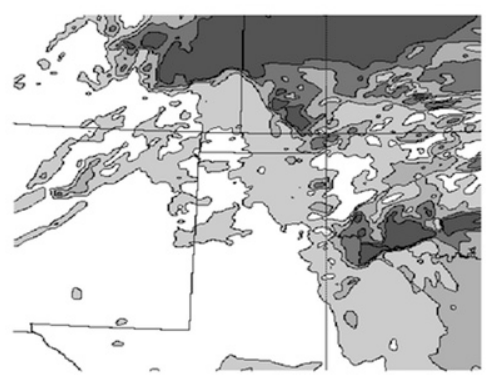

FIG. 13. (a) Severe reports for the 17 Apr 1970 TO, as provided by the plotting program SVRPLOT. (b) Two-day forecast radar reflectivity factor (shading above $40 \mathrm{dBZ}$ ) valid at 0000 UTC 18 Apr 1970. (c) As in (b), but for LCL (m AGL; shading as in Fig. 6b). (d) As in (b), but for $0-1-\mathrm{km}$ SREH $\left(\mathrm{m}^{2} \mathrm{~s}^{-2}\right.$; shading as in Fig. 6a).

occurred. (Little meridional bias was observed in the other cases.) This simulated convection existed in close proximity to the surface low and the corresponding upper-level shortwave trough. The synoptic-scale lift was substantial, and any environmental cap in place was eroded in these simulations. However, south and east of the synoptic-scale system, much of the warm sector was characterized by higher instability, a stronger cap (e.g., from an elevated mixed layer advecting into the warm sector), and weaker synoptic-scale lift. Convective initiation is more difficult to simulate in these locations (e.g., Moller 2001), creating the poleward bias in simulated deep convection observed in these cases.
The analysis of simulated deep convection in the outbreak forecasts provided insight into the tendency for TOs to be supercellular and PNOs to be associated more often with mesoscale convective systems, squall lines, bow echoes, derechos, etc. Subjective analysis found that at least $70 \%$ of the TOs featured simulated deep convection with supercellular characteristics (Table 1), whereas PNOs had a much lower frequency, near or below $20 \%$ (Table 2). This result may explain why deeplayer shear is a helpful discriminator (see Rasmussen and Blanchard 1998) and suggests that the convective mode frequently does have implications on the type of outbreak that occurs.

TABLE 7. Reclassifications of TO simulations when accounting for phase errors and temporal evolution. Abbreviations as in Table 1.

\begin{tabular}{cccc}
\hline \hline Outbreak case & New classifications & Outbreak case & New classifications \\
\hline 25 Sep 1973 (1-day) & H to VH & 31 May 1985 (2-day) & H to VH \\
8 Jun 1974 (1-day) & H to VH & 2 Jun 1990 (2-day) & H to VH \\
10 Apr 1979 (1-day) & H to VH & 26 Apr 1994 (2-day) & L to M \\
26 Apr 1984 (1-day) & H to VH & 8 Apr 1994 (2-day) & H to VH \\
26 Apr 1994 (1-day) & L to M & 23 Nov 2001 (2-day) & H to VH \\
8 Apr 1999 (1-day) & H to VH & 6 May 2003 (2-day) & H to VH \\
6 May 2003 (1-day) & M to H & 27 May 1973 (3-day) & H to VH \\
17 Apr 1970 (2-day) & M to H & 7 Jun 1984 (3-day) & M to H Apr 1999 (3-day) \\
15 Mar 1982 (2-day) & H to VH & & H to VH \\
7 Jun 1984 (2-day) & L to M & & \\
\hline
\end{tabular}


TABLE 8. Comparison of classifications of TOs when considering only the actual location of the outbreak at the valid time of 0000 UTC (00) vs accounting for phase/location errors and temporal evolution of outbreaks (all). All other abbreviations as in the text.

\begin{tabular}{lccc}
\hline \hline Forecast type & 1 day & 2 day & 3 day \\
\hline TO-VH (00) & 28 & 24 & 22 \\
TO-H (all) & 33 & 30 & 24 \\
TO-H (00) & 15 & 17 & 22 \\
TO-H (all) & 11 & 12 & 22 \\
TO-M (00) & 4 & 3 & 2 \\
TO-M (all) & 4 & 4 & 1 \\
TO-L (00) & 3 & 6 & 4 \\
TO-L (all) & 2 & 4 & 4 \\
\hline
\end{tabular}

Simulated deep convection modified other severeweather parameters besides CAPE and CIN. LCLs were altered substantially in some simulations (Fig. 14); sometimes, bulk shear readings also were affected (not shown). In these simulations, analyzing the preconvective environment was necessary for the correct diagnosis of outbreak type, giving more credence to looking at multiple times during the outbreak day for proper outbreak discrimination.

\section{Conclusions}

In this study, 50 tornado outbreaks (TOs) and 50 primarily nontornadic outbreaks (PNOs) were simulated using the WRF to determine if the model is capable of distinguishing outbreak type using synoptic-scale input. One PNO was excluded from the study because it was found that the outbreak occurred during the early morning hours, whereas the rest of the outbreaks occurred at or near early evening. These simulations were run for 1-, 2-, and 3-day forecasts. The cases were classified into one of four categories according to the number of severeweather parameters that favored the correct type of outbreak. Results of the study include the following:

TABLE 9. The number of TOs in which little or no convection was simulated for each forecast period. NC stands for "no convection." Here, N/A indicates not applicable.

\begin{tabular}{ccccc}
\hline \hline Month & Tot & 1-day NC & 2-day NC & 3-day NC \\
\hline Jan & 1 & 0 & 0 & 0 \\
Feb & 2 & 0 & 0 & 0 \\
Mar & 7 & 0 & 0 & 0 \\
Apr & 12 & 0 & 2 & 0 \\
May & 14 & 1 & 2 & 4 \\
Jun & 6 & 0 & 0 & 0 \\
Jul & 0 & N/A & N/A & N/A \\
Aug & 0 & N/A & N/A & N/A \\
Sep & 1 & 0 & 1 & 0 \\
Oct & 0 & N/A & N/A & N/A \\
Nov & 6 & 0 & 1 & 1 \\
Dec & 1 & 0 & 0 & 0 \\
\hline
\end{tabular}

TABLE 10. As in Table 9, but for the PNOs.

\begin{tabular}{ccccc}
\hline Month & Tot & 1-day NC & 2-day NC & 3-day NC \\
\hline Jan & 0 & N/A & N/A & N/A \\
Feb & 0 & N/A & N/A & N/A \\
Mar & 0 & N/A & N/A & N/A \\
Apr & 5 & 0 & 0 & 0 \\
May & 9 & 1 & 2 & 1 \\
Jun & 9 & 0 & 0 & 0 \\
Jul & 17 & 0 & 3 & 3 \\
Aug & 7 & 0 & 0 & 1 \\
Sep & 1 & 0 & 0 & 0 \\
Oct & 1 & 0 & 0 & 0 \\
Nov & 1 & 1 & 1 & 1 \\
Dec & 0 & N/A & N/A & N/A \\
\hline
\end{tabular}

- Several severe-weather parameters were helpful in the analysis of the forecasts to determine if the WRF was capable of distinguishing outbreak type properly. Parameters favored shear variables (e.g., 0-1-, $0-3-$, and $0-6-\mathrm{km}$ bulk shear; $0-1-$ and $0-3-\mathrm{km}$ SREH; and BRNSHR), EHI, and LCL. The magnitudes and the spatial structures of the severe parameters were found to be helpful in the discrimination of outbreaks.

- Generally, thermodynamic instability parameters (e.g., CAPE) were not useful for discrimination. Convective modification and seasonal dependence were two reasons this was the case.

- Each outbreak type favored particular forecast synoptic patterns. The TOs commonly were associated with Miller's (1972) types A, B, and D synoptic patterns, whereas PNOs commonly were associated with Miller's (1972) types C and E synoptic patterns.

- There was no strong evidence to suggest that regional dependencies affect the model's ability to distinguish outbreak type.

- With only synoptic-scale data to initialize the model simulations, more than $80 \%$ of TOs and PNOs were discriminated correctly up to 3 days in advance when analyzing the region in which the outbreak occurred at the valid time of the outbreak. Accounting for the temporal evolution of outbreaks and the model's phase/location errors resulted in an improvement of case classifications. These results suggest that synopticscale processes play a major role in the occurrence or absence of tornado outbreaks and that inclusion of higher-resolution data is not necessary to make these distinctions most of the time.

- Most of the outbreaks that were difficult to discriminate occurred during the spring and early summer. This may indicate that the severe-weather parameters selected to distinguish outbreaks have seasonal dependence. 


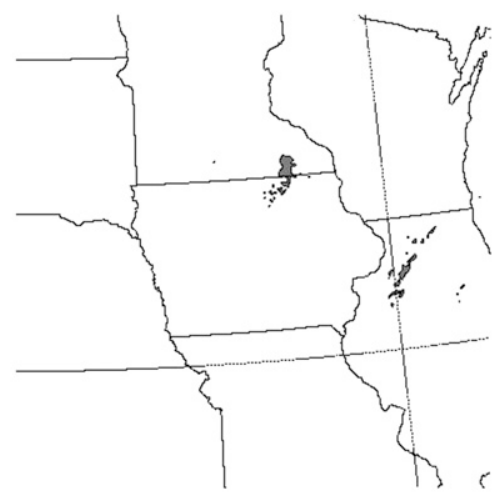

c)

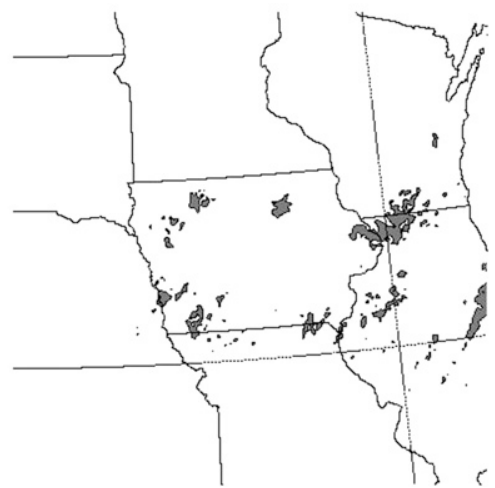

b)

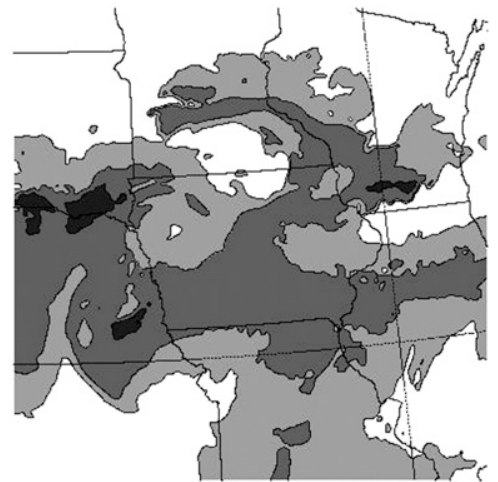

d)

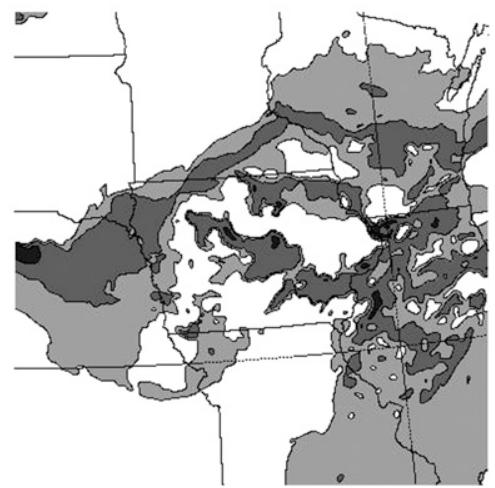

FIG. 14. (a) Forecast radar reflectivity factor (shading above $40 \mathrm{dBZ}$ ) valid at 1800 UTC 27 May 1995. (b) Forecast LCL (m AGL; shading as in Fig. 6b) valid at 180027 May 1995. (c) Same as (a), but valid at 0000 UTC 28 May 1995. (d) As in (b), but valid at 0000 UTC 28 May 1995. All forecasts from the simulation initialized at 0000 UTC 25 May 1995 of the 27 May 1995 TO. Tornado reports for the 27 May 1995 TO can be found in Fig. 4g.

More work is needed to determine the role of the synoptic scale in the development of TOs. Objective techniques to analyze these simulations are currently being tested. If the objective techniques prove to confirm many of the findings of this study, this will lead to greater confidence in the model's ability to distinguish outbreak type. Moreover, verification of the forecasts is also planned to determine more quantitatively the association between forecast accuracy and the diagnosis of outbreak type.

Before these techniques can be used in a forecast setting, additional research is required. Because the model appears to have more difficulty distinguishing outbreak type in the spring and early summer, cases focused on this time of year must be considered. Moreover, a majority of severe-weather outbreaks cannot be considered primarily nontornadic, but clearly are not major tornado outbreaks, either. Research into how the WRF can discriminate these cases from TOs and PNOs is needed. Analysis of the predicted vertical velocity and vertical vorticity fields may also provide beneficial information regarding outbreak discrimination. The use of ensembles to investigate uncertainties in the forecasts and correct diagnosis of outbreak type should be considered. Finally, sets of pre-event composites for each type of outbreak could be created, initialized in the WRF, and analyzed to determine if the model is diagnosing the correct type of outbreak. In essence, these would be mesoscale model simulations of idealized synoptic-scale conditions, which hitherto (to our knowledge) have not been conducted previously. Such research could result in an enhanced physical understanding of the association between the synoptic environment and tornado outbreaks. Investigation of these critical topics is under way.

Acknowledgments. This research was supported by NSF Grant ATM-0527934 and NSF is gratefully acknowledged. The authors thank David Stensrud of the National Severe Storms Laboratory, Rich Thompson and 
Steve Weiss of the Storm Prediction Center, and two anonymous reviewers for their helpful comments, which have greatly improved the manuscript. We also thank Dr. Henry Neeman and the University of Oklahoma Supercomputing Center for Education and Research (OSCER) administrators for their assistance in providing the computational facilities used for this project and Kevin Thomas for his help in compiling and troubleshooting WRF. All model simulations were performed and all model output was stored on the University of Oklahoma supercomputer known as Topdawg (see online at http://www.oscer.ou.edu).

\section{REFERENCES}

Baldwin, M. E., J. S. Kain, and M. P. Kay, 2002: Properties of the convection scheme in NCEP's Eta Model that affect forecast sounding interpretation. Wea. Forecasting, 17, 1063-1079.

Beebe, R. G., 1955: Types of air masses in which tornadoes occur. Bull. Amer. Meteor. Soc., 36, 349-350.

, 1956: Tornado composite charts. Mon. Wea. Rev., 84, 127-142.

Blackadar, A. K., 1957: Boundary layer wind maxima and their significance for the growth of nocturnal inversions. Bull. Amer. Meteor. Soc., 38, 283-290.

Brooks, H. E., C. A. Doswell III, and R. A. Maddox, 1992: On the use of mesoscale and cloud-scale models in operational forecasting. Wea. Forecasting, 7, 352-362.

$\longrightarrow,-$ _ and nontornadic mesocyclones. Wea. Forecasting, 9, 606-618.

- - _ and R. B. Wilhelmson, 1994b: On the role of midtropospheric winds in the evolution and maintenance of lowlevel mesocyclones. Mon. Wea. Rev., 122, 126-136.

,$- \ldots$, and M. P. Kay, 2003a: Climatological estimates of local daily tornado probability for the United States. Wea. Forecasting, 18, 626-640.

_ J. W. Lee, and J. P. Craven, 2003b: The spatial distributions of severe thunderstorm and tornado environments from global reanalysis data. Atmos. Res., 67-68, 73-94.

Brown, B. G., and A. H. Murphy, 1996: Verification of aircraft icing forecasts: The use of standard measures and meteorological covariates. Preprints, 13th Conf. on Probability and Statistics in the Atmospheric Sciences, San Francisco, CA, Amer. Meteor. Soc., 251-252.

Bunkers, M. J., 2002: Vertical wind shear associated with leftmoving supercells. Wea. Forecasting, 17, 845-855.

Colby, F. P., Jr., 1984: Convective inhibition as a predictor of convection during AVE-SESAME II. Mon. Wea. Rev., 112, 2239-2252.

Collins, W. G., and L. S. Gandin, 1990: Comprehensive hydrostatic quality control at the National Meteorological Center. Mon. Wea. Rev., 118, 2754-2767.

- and - 1992: Complex quality control of rawinsonde heights and temperatures (CQCHT) at the National Meteorological Center. NMC Office Note 390, 30 pp. [Available from NOAA/NCEP, 5200 Auth Rd., Washington, DC 20233.]

Coniglio, M. C., and D. J. Stensrud, 2004: Interpreting the climatology of derechos. Wea. Forecasting, 19, 595-605.

Craven, J. P., H. E. Brooks, and J. A. Hart, 2002a: Baseline climatology of sounding derived parameters associated with deep, moist convection. Preprints, 21st Conf. on Severe Local Storms, San Antonio, TX, Amer. Meteor. Soc., 643-646.
_ R. E. Jewell, and H. E. Brooks, 2002b: Comparison between observed convective cloud-base heights and lifting condensation level for two different lifted parcels. Wea. Forecasting, 17, 885-890.

Davies, J. M., and R. Johns, 1993: Some wind and instability parameters associated with strong and violent tornadoes. Part I: Wind shear and helicity. The Tornado: Its Structure, Dynamics, Prediction and Hazards, Geophys. Monogr., Vol. 79, Amer. Geophys. Union, 573-582.

Davies-Jones, R., D. Burgess, and M. Foster, 1990: Test of helicity as a tornado forecast parameter. Preprints, 16th Conf. on Severe Local Storms, Kananaskis Park, AB, Canada, Amer. Meteor. Soc., 588-592.

Deng, A., and D. R. Stauffer, 2006: On improving 4-km mesoscale model simulations. J. Appl. Meteor., 45, 361-381.

Derber, J. D., D. F. Parrish, and S. J. Lord, 1991: The new global operational analysis system at the National Meteorological Center. Wea. Forecasting, 6, 538-547.

Doswell, C. A., III, 2007a: Historical overview of severe convective storms research. Electron. J. Severe Storms Meteor., 2 (1), $1-25$.

$\ldots$, 2007b: Small sample size and data quality issues illustrated using tornado occurrence data. Electron. J. Severe Storms Meteor., 2 (5), 1-16.

_ and L. F. Bosart, 2001: Extratropical synoptic-scale processes and severe convection. Severe Convective Storms, Meteor. Monogr., No. 27, Amer. Meteor. Soc., 1-27.

— derechos and supercells: An assessment of similarities and differences. Atmos. Res., 67-68, 117-133.

_, R. H. Johns, and S. J. Weiss, 1993: Tornado forecasting: A review. The Tornado: Its Structure, Dynamics, Prediction and Hazards, Geophys. Monogr., Vol. 79, Amer. Geophys. Union, 557-571.

— H. E. Brooks, and M. P. Kay, 2005: Climatological estimates of daily local nontornadic severe thunderstorm probability for the United States. Wea. Forecasting, 20, 577-595.

_ , R. Edwards, R. L. Thompson, J. A. Hart, and K. C. Crosbie, 2006: A simple and flexible method for ranking severe weather events. Wea. Forecasting, 21, 939-951.

Droegemeier, K. K., S. M. Lazarus, and R. Davies-Jones, 1993: The influence of helicity on numerically simulated convective storms. Mon. Wea. Rev., 121, 2005-2029.

Dudhia, J., 1989: Numerical study of convection observed during the winter monsoon experiment using a mesoscale twodimensional model. J. Atmos. Sci., 46, 3077-3107.

Fawbush, W. J., and R. C. Miller, 1952: A mean sounding representative of the tornadic air mass environment. Bull. Amer. Meteor. Soc., 33, 303-307.

— and - 1954: A basis for forecasting peak wind gusts in nonfrontal thunderstorms. Bull. Amer. Meteor. Soc., 35, 14-19.

Galway, J. G., 1975: Relationship of tornado deaths to severe weather watch areas. Mon. Wea. Rev., 103, 737-741.

_ 1977: Some climatological aspects of tornado outbreaks. Mon. Wea. Rev., 105, 477-484.

Glickman T. S. Ed., 2000: Glossary of Meteorology. 2nd ed. Amer. Meteor. Soc., 855 pp.

Grazulis, T. P., 1993: Significant Tornadoes 1680-1991. Environmental Films, 1326 pp.

Grell, G. A., and D. Devenyi, 2002: A generalized approach to parameterizing convection combining ensemble and data assimilation techniques. Geophys. Res. Lett., 29, 1693, doi: 10.1029/2002GL015311. 
Hart, J. A., 1993: SVRPLOT: A new method of accessing and manipulating the NSSFC Severe Weather Database. Preprints, 17th Conf. on Severe Local Storms, St. Louis, MO, Amer. Meteor. Soc., 40-41.

- and W. Korotky, 1991: The SHARP workstation v1.50 users guide. NOAA/National Weather Service, $30 \mathrm{pp}$. [Available from NWS Eastern Region Headquarters, 630 Johnson Ave., Bohemia, NY 11716.]

Holton, J. R., 1992: An Introduction to Dynamic Meteorology. 3rd ed. Academic Press, 511 pp.

Hong, S.-Y., and H.-L. Pan, 1996: Nonlocal boundary layer vertical diffusion in a medium-range forecast model. Mon. Wea. Rev., 124, 2322-2339.

_ - H.-M. Juang, and Q. Zhao, 1998: Implementation of prognostic cloud scheme for a regional spectral model. Mon. Wea. Rev., 126, 2621-2639.

Horgan, K. L., D. L. Schultz, J. E. Hales Jr., S. F. Corfidi, and R. H. Johns, 2007: A five-year climatology of elevated severe convective storms in the United States east of the Rocky Mountains. Wea. Forecasting, 22, 1031-1044.

Igau, R. C., and J. W. Nielsen-Gammon, 1998: Low-level jet development during a numerically simulated return flow event. Mon. Wea. Rev., 126, 2972-2990.

James, R. P., P. M. Markowski, and J. M. Fritsch, 2006: Bow echo sensitivity to ambient moisture and cold pool strength. Mon. Wea. Rev., 134, 950-964.

Jankov, I., W. A. Gallus Jr., M. Segal, B. Shaw, and S. E. Koch, 2005: The impact of different WRF model physical parameterizations and their interactions on warm season MCS rainfall. Wea. Forecasting, 20, 1048-1060.

Ji, M., A. Kumar, and A. Leetmaa, 1994: A multiseason climate forecast system at the National Meteorological Center. Bull. Amer. Meteor. Soc., 75, 557-569.

Johns, R. H., 1984: A synoptic climatology of northwest-flow severe weather outbreaks. Part II: Meteorological parameters and synoptic patterns. Mon. Wea. Rev., 112, 449-464.

_ , and C. A. Doswell III, 1992: Severe local storms forecasting. Wea. Forecasting, 7, 588-612.

_ J. Davies, and P. Leftwich, 1993: Some wind and instability parameters associated with strong and violent tornadoes. Part II: Variations in the combinations of wind and instability parameters. The Tornado: Its Structure, Dynamics, Prediction and Hazards, Geophys. Monogr., Vol. 79, Amer. Geophys. Union, 583-590.

Kalnay, E., and Coauthors, 1996: The NCEP/NCAR 40-Year Reanalysis Project. Bull. Amer. Meteor. Soc., 77, 437-471.

Kanamitsu, M., 1989: Description of the NMC global data assimilation and forecast system. Wea. Forecasting, 4, 334-342.

_ - and Coauthors, 1991: Recent changes implemented into the global forecast system at NMC. Wea. Forecasting, 6, 425-435.

Kerr, B. W., and G. L. Darkow, 1996: Storm-relative winds and helicity in the tornadic thunderstorm environment. Wea. Forecasting, 11, 489-505.

Lin, Y.-L., R. D. Farley, and H. D. Orville, 1983: Bulk parameterization of the snow field in a cloud model. J. Climate Appl. Meteor., 22, 1065-1092.

Maddox, R. A., 1976: An evaluation of tornado proximity wind and stability data. Mon. Wea. Rev., 104, 133-142.

Miller, R., 1972: Notes on analysis and severe-storm forecasting procedures of the Air Force Global Weather Center. Air Weather Service Tech. Rep. 200 (rev.), Air Weather Service, Scott Air Force Base, IL, 184 pp. [Available online at http://
stinet.dtic.mil/cgi-bin/GetTRDoc?AD = AD744042\&Location= $\mathrm{U} 2 \&$ doc $=$ GetTRDoc.pdf.]

Mlawer, E. J., S. J. Taubman, P. D. Brown, M. J. Iacono, and S. A. Clough, 1997: Radiative transfer for inhomogeneous atmospheres: RRTM, a validated correlated-k model for the longwave. J. Geophys. Res., 102 (D14), 16 663-16 682.

Molinari, J., and M. Dudek, 1992: Parameterization of convective precipitation in mesoscale numerical models: A critical review. Mon. Wea. Rev., 120, 326-344.

Moller, A. R., 2001: Severe local storms forecasting. Severe Convective Storms, Meteor. Monogr., No. 50, Amer. Meteor. Soc., 433-480.

Monteverdi, J. P., C. A. Doswell III, and G. S. Lipari, 2003: Shear parameter thresholds for forecasting tornadic thunderstorms in northern and central California. Wea. Forecasting, 18, 357-370.

Orlanski, I., 1975: A rational subdivision of scales for atmospheric processes. Bull. Amer. Meteor. Soc., 56, 527-530.

Parrish, D. F., and J. C. Derber, 1992: The National Meteorological Center's spectral statistical interpolation analysis system. Mon. Wea. Rev., 120, 1747-1763.

Pautz, M. E., 1969: Severe local storm occurrences, 1955-1967. ESSA Tech. Memo. WBTM FCST12, Washington, DC, 77 pp.

Porter, J. M., L. L. Means, J. E. Hovde, and W. B. Chappell, 1955: A synoptic study of squall lines in the north central United States. Bull. Amer. Meteor. Soc., 36, 390-396.

Rasmussen, E. N., and D. O. Blanchard, 1998: A baseline climatology of sounding-derived supercell and tornado forecast parameters. Wea. Forecasting, 13, 1148-1164.

Reynolds, R. W., and T. M. Smith, 1994: Improved global sea surface temperature analyses using optimum interpolation. $J$. Climate, 7, 929-948.

Schaefer, J. T., 1986: Severe thunderstorm forecasting: A historical perspective. Wea. Forecasting, 1, 164-189.

Skamarock, W. C., J. B. Klemp, J. Dudhia, D. O. Gill, D. M. Barker, W. Wang, and J. G. Powers, 2005: A description of the Advanced Research WRF Version 2. NCAR Tech. Note NCAR/TN-468+STR, 88 pp. [Available from UCAR Communications, P.O. Box 3000, Boulder, CO 80307.]

Stensrud, D. J., 1996: Importance of low-level jets to climate: A review. J. Climate, 9, 1698-1711.

, and J. M. Fritsch, 1994: Mesoscale convective systems in weakly forced large-scale environments. Part III: Numerical simulations and implications for numerical forecasting. Mon. Wea. Rev., 122, 2084-2104.

— J. V. Cortinas, and H. E. Brooks, 1997: Discriminating between tornadic and nontornadic thunderstorms using mesoscale model output. Wea. Forecasting, 12, 613-632.

Thompson, R. L., and R. Edwards, 2000: An overview of environmental conditions and forecast implications of the 3 May 1999 tornado outbreak. Wea. Forecasting, 15, 682-699.

,- _ J. A. Hart, K. L. Elmore, and P. Markowski, 2003: Close proximity soundings with supercell environments obtained from the Rapid Update Cycle. Wea. Forecasting, 18, 1243-1261.

Wicker, L. J., and W. C. Skamarock, 2002: Time splitting methods for elastic models using forward time schemes. Mon. Wea. Rev., 130, 2088-2097.

Woollen, J. S., 1991: New NMC operational OI quality control. Preprints, Ninth Conf. on Numerical Weather Prediction, Denver, CO, Amer. Meteor. Soc., 24-27.

-, E. Kalnay, L. Gandin, W. Collins, S. Saba, R. Kistler, M. Kanamitsu, and M. Chelliah, 1994: Quality control in the reanalysis system. Preprints, 10th Conf. on Numerical Weather Prediction, Portland, OR, Amer. Meteor. Soc., 13-14. 